\title{
Adaptive Robust Fault-Tolerant Synchronization Control for a Dual Redundant Hydraulic Actuation System with Common-Mode Fault
}

\author{
Ting Li $\mathbb{D}$, Ting Yang $\mathbb{D}$, Yuyan Cao, Rong Xie, and Xinmin Wang \\ School of Automation, Northwestern Polytechnical University, Xian 710129, China \\ Correspondence should be addressed to Ting Li; liting513@mail.nwpu.edu.cn
}

Received 31 May 2018; Revised 9 September 2018; Accepted 12 September 2018; Published 4 October 2018

Academic Editor: Asier Ibeas

Copyright (C) 2018 Ting Li et al. This is an open access article distributed under the Creative Commons Attribution License, which permits unrestricted use, distribution, and reproduction in any medium, provided the original work is properly cited.

\begin{abstract}
This paper investigates the fault-tolerant synchronization control (FTSC) problem for a dual redundant hydraulic actuation system (DRHAS), which works on active/active (A/A) mode and suffers from a kind of common-mode fault (CMF), i.e., internal leakage faults occurring in both hydraulic actuator (HA) channels simultaneously due to a common cause. Firstly, in order to follow the position command and synchronize the force outputs of the two channels, a desired trajectory generator derived from the dynamics of the control surface is employed. Then, considering model uncertainties and nonlinear dynamics of the plant, an FTSC controller is designed based on adaptive robust control (ARC) theory and backstepping technology. The controller parameters, closely related to the fault parameters, are updated online to make the controller adapt to the fault condition only when the system performance degradation exceeds a prescribed tolerable level. It has been verified that the proposed FTSC scheme can guarantee the bounded stability of output tracking error system under common-mode fault. Finally, simulation results under two scenarios demonstrate the effectiveness of the proposed FTSC scheme.
\end{abstract}

\section{Introduction}

For safety and reliability consideration, the primary flight control systems for modern airplanes have universally adopted redundant hydraulic actuation systems (RHAS) to drive important control surfaces. One typical example is the Airbus A320, in which both ailerons are driven by a dual redundant hydraulic actuation system (DRHAS), the rudder is driven by a triply redundant hydraulic actuation system (TRHAS), and the elevators are driven by DRHASs [1].

In a typical RHAS configuration, several similar hydraulic actuators (HA), which are supplied from three redundant hydraulic power sources, connect to a common control surface in parallel. Each HA includes an electro-hydraulic servo valve (EHSV), a hydraulic cylinder, and other accessories. There are two distinct operating modes for a RHAS, i.e., active/active (A/A) mode and active/standby (A/S) mode. In $\mathrm{A} / \mathrm{A}$ mode, all $\mathrm{HA}$ channels are working together at the same point and their outputs can be summed in three ways, i.e., parallel force summing, parallel velocity summing, and parallel position summing [2]. Among them, the parallel force summing is the most common choice for the primary flight control system of airliners, such as A320, A380, B747, and B787. In A/S mode, the HA channels operate independently and only one channel is working at one time while others are isolated by bypass-valves.

The RHAS on A/A mode has a potential risk of suffering from common-mode fault (CMF), which is a coincidence of fault states of components in separate channels caused by the same event(s) [3]. As stated in [4], the CMF is difficult to predict or to avoid by system design as its nature is unexpected or unrecognized. Reference [5] shows that design faults which are not found and removed at stages prior to the operational stage constitute a major part of CMF in redundant system. In addition, CMF can also occur due to external causes such as environmental disturbance and power supply disturbance. Considering the critical functions of the RHAS in primary flight control systems, CMF tolerance is very important. 
More recently, theoretical research on fault-tolerant control (FTC) problems, especially on active fault-tolerant control (AFTC) problems for hydraulic actuation system, is receiving more and more attention. However, most research focuses on the FTC problems for single-channel hydraulic actuator (SHA). The existing design methods include quantitative feedback theory (QFT) [6, 7], adaptive robust control (ARC) [8-10], and intelligent control [11]. Among them, [711] belong to the AFTC method, which needs to employ real-time fault detection and diagnosis (FDD) module to provide up to date information about the true status of a system [12]. The FDD methods in [7-11] include neural network [7], adaptive robust observer [8], parameter adaptive methodology [9], and stochastic filtering theory [10, 11].

Compared with SHA, to the best of the authors' knowledge, the studies on FTC strategies for the RHAS, especially for the RHAS suffering from CMF, are very limited. In [13, 14], a disturbance-decoupled robust adaptive observer was designed and applied to a RHAS-driven elevator for faulty parameters estimation. A set of local fuzzy PI controllers with respect to different operating conditions of the system were designed. Then, a tolerant control output was generated by synthesizing the output of each local controller according to the obtained fault information. However, the FTC controllers are designed on the basis of an approximate linear model, dynamics of the control surface, and model uncertainties of the plant are not considered in the existing results.

To deal with the control problem for nonlinear system with model uncertainties, a great number of nonlinear control schemes have been developed by employing backstepping technology. For example, in [15-18], several backsteppingbased adaptive neural (or fuzzy) control schemes were presented and neural networks (or fuzzy logic systems) were employed to approximate the unmodeled dynamics. However, the application of these schemes is limited by the large computation load. In [19], a FTC scheme based on adaptive sliding mode backstepping was proposed for a nonlinear system under external disturbances and faults. In $[20,21]$, with the aid of the backstepping technology, several nonlinear ARC controllers were constructed, in which the adaptive part was employed to handle parametric uncertainties and the robust part was mainly used to accommodate the unmodeled dynamics. To the authors' knowledge, a critical issue for FTC design is the limited amount of time for the control system reconfiguration [12]. Therefore, due to its simple structure and fast execution speed, the backstepping-based ARC scheme is more suitable for the FTC design for RHAS with model uncertainties.

The force fighting between HA channels is an inherent problem for the RHAS which works on A/A mode and has a parallel force summing configuration, namely, the HAs fight against each other to find an equilibrium point [22].The primary cause of the force fighting problem lies in the unsynchronized force outputs of HAs. In normal situation, manufacturing tolerances and individual nonlinear property of each HA can lead to unsynchronized force outputs. Moreover, the faults occurring in the RHAS will aggravate the unsynchronization of the force outputs and finally enlarge the force fighting between HA channels. Since a serious force fighting may slow down the system response, reduce the position tracking accuracy, or even damage the control surface, solving the problem of unsynchronized force outputs under fault conditions is very important for the FTC controller design for RHAS. Recently, several control strategies have been developed for force outputs synchronization, such as pressure differential equalization control [23], decoupling control [24], and motion state synchronization control $[25,26]$. However, to the authors' knowledge, most of the results are based on linear RHAS models without consideration of nonlinear dynamics and model uncertainties. Besides, no FTC scheme for RHAS can achieve force outputs synchronization control for HAs.

In this paper, considering the nonlinear dynamics of the hydraulic system, model uncertainties, and dynamics of the control surface, an adaptive robust fault-tolerant synchronization control (FTSC) scheme is proposed for a DRHAS suffering from an internal leakage CMF. The contributions of the paper are twofold: (1) Based on the introduction of two reference trajectories, a general nonlinear model for the DRHAS with model uncertainties and an internal leakage CMF is constructed to facilitate the controller design. (2) A novel FTSC controller based on ARC control and backstepping technology is designed, which can handle the CMF tolerant control problem and the force outputs synchronization control problem simultaneously. Simulation results further demonstrate the effectiveness of the proposed scheme.

The rest of the paper is organized as follows. The model for a DRHAS working on A/A mode is given in Section 2. Then, the FTSC scheme which includes desired trajectory generation, model transformation, and FTSC controller design is presented in Section 3. Simulation results are provided in Section 4. Finally, a conclusion is given in Section 5 .

\section{Model of a Dual Redundant Hydraulic Actuation System}

The structure of a typical DRHAS is shown in Figure 1. Two hydraulic actuators, powered by different hydraulic power sources, connect to a common control surface and operate on A/A mode. Each HA mainly consists of an EHSV and a hydraulic cylinder.

2.1. Model of the Hydraulic Actuator. The two HAs have the same structure, and the mathematical model for $\mathrm{HA}_{1}$ is presented below.

The model of the EHSV can be described by a proportional function $[27,28]$ as

$$
x_{\mathrm{v} 1}=k_{\mathrm{i} 1} u_{1}
$$

where $x_{\mathrm{v} 1}$ is the servo valve displacement, $u_{1}$ is the control input, and $k_{\mathrm{i} 1}$ is the servo valve gain.

The cylinder dynamic can be represented by

$$
\ddot{x}_{\mathrm{h} 1}=\frac{1}{m_{\mathrm{h} 1}}\left[A_{1} P_{\mathrm{h} 11}-A_{2} P_{\mathrm{h} 12}-B_{\mathrm{h} 1} \dot{x}_{\mathrm{h} 1}-F_{\mathrm{h} 1}-d_{1}\right]
$$




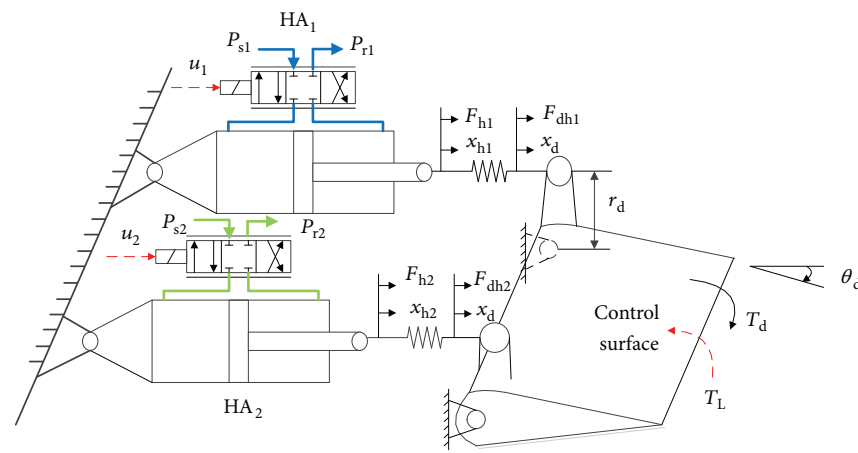

FIGURE 1: Structure diagram of a DRHAS operating on A/A mode.

where $x_{\mathrm{h} 1}$ is the piston rod displacement, $m_{\mathrm{h} 1}$ is the piston mass, $A_{1}$ is the piston area of the active chamber, $A_{2}$ is the piston area of the passive chamber, $B_{\mathrm{h} 1}$ is the damping coefficient, $F_{\mathrm{h} 1}$ is the external load of the cylinder, and $d_{1}$ is the model uncertainty which includes unmodeled nonlinear dynamics and lumped parameter variations.

The chamber pressures of the cylinder, i.e., $P_{\mathrm{h} 11}$ and $P_{\mathrm{h} 12}$, are calculated by

$$
\begin{aligned}
& \dot{P}_{\mathrm{h} 11}=\frac{\beta_{e}}{V_{\mathrm{h} 11}}\left(-A_{1} \dot{x}_{\mathrm{h} 1}-q_{\mathrm{h} 1}+Q_{\mathrm{h} 11}\right), \\
& \dot{P}_{\mathrm{h} 12}=\frac{\beta_{e}}{V_{\mathrm{h} 12}}\left(A_{2} \dot{x}_{\mathrm{h} 1}+q_{\mathrm{h} 1}-\mathrm{Q}_{\mathrm{h} 12}\right)
\end{aligned}
$$

where $\beta_{e}$ is the effective oil bulk modulus, $V_{\mathrm{h} 11}=V_{10}+A_{1} x_{\mathrm{h} 1}$ is the volume of the active chamber, $V_{\mathrm{h} 12}=V_{20}-A_{2} x_{\mathrm{h} 1}$ is the volume of the passive chamber, and $V_{10}$ and $V_{20}$ are the initial volumes of two chambers, respectively. $Q_{\mathrm{h} 11}$ is the supply flow rate of the active chamber and $Q_{\mathrm{h} 12}$ is the return flow rate of the passive chamber.

When the DRHAS suffers from an internal leakage CMF, i.e., the internal leakage faults occurring in both HAs simultaneously due to a common cause, the internal leakage flow rate $q_{\mathrm{h} 1}$ of $\mathrm{HA}_{1}$ can be modeled by [9]

$$
\begin{aligned}
q_{\mathrm{h} 1}= & C_{\mathrm{i} 1}\left(P_{\mathrm{h} 11}-P_{\mathrm{h} 12}\right) \\
& +\beta_{1}\left(t-t_{\mathrm{f}}\right) C_{\mathrm{t} 1} \sqrt{\left|P_{\mathrm{h} 11}-P_{\mathrm{h} 12}\right|} \operatorname{sgn}\left(P_{\mathrm{h} 11}-P_{\mathrm{h} 12}\right)
\end{aligned}
$$

where $C_{\mathrm{i} 1}$ is the normal internal leakage coefficient, $C_{\mathrm{t} 1}$ represents the fault internal leakage coefficient, $\operatorname{sgn}(\cdot)$ is the sign function, $t_{\mathrm{f}}$ is the fault occurrence time, $\beta_{1}\left(t-t_{\mathrm{f}}\right)$ is the time profile of the fault which can be described by

$$
\beta_{1}\left(t-t_{\mathrm{f}}\right)= \begin{cases}0 & t<t_{\mathrm{f}} \\ 1-e^{-\mu_{1}\left(t-t_{\mathrm{f}}\right)} & t \geq t_{\mathrm{f}}\end{cases}
$$

and $\mu_{1}$ is a positive constant which represents the fault evolution speed.
The flow rates $Q_{\mathrm{h} 11}$ and $Q_{\mathrm{h} 12}$ can be calculated by $Q_{\mathrm{h} 11}$

$$
\begin{aligned}
& =k_{q} k_{\mathrm{i} 1} u_{1}\left[s\left(u_{1}\right) \sqrt{P_{\mathrm{s} 1}-P_{\mathrm{h} 11}}+s\left(-u_{1}\right) \sqrt{P_{\mathrm{h} 11}-P_{\mathrm{r} 1}}\right], \\
& \mathrm{Q}_{\mathrm{h} 12} \\
& =k_{q} k_{\mathrm{i} 1} u_{1}\left[s\left(u_{1}\right) \sqrt{P_{\mathrm{h} 12}-P_{\mathrm{r} 1}}+s\left(-u_{1}\right) \sqrt{P_{\mathrm{s} 1}-P_{\mathrm{h} 12}}\right]
\end{aligned}
$$

where $k_{q}=C_{\mathrm{d}} \omega \sqrt{2 / \rho}$ is the flow rate gain of the servo valve, $P_{s 1}$ is the supply oil pressure, $P_{\mathrm{r} 1}$ is the return oil pressure, and $s(x)$ is defined as

$$
s(x) \triangleq \begin{cases}1 & x \geq 0 \\ 0 & x<0\end{cases}
$$

For simplicity, we define

$$
\begin{aligned}
& R_{\mathrm{h} 11}=s\left(u_{1}\right) \sqrt{P_{\mathrm{s} 1}-P_{\mathrm{h} 11}}+s\left(-u_{1}\right) \sqrt{P_{\mathrm{h} 11}-P_{\mathrm{r} 1}} \\
& R_{\mathrm{h} 12}=s\left(u_{1}\right) \sqrt{P_{\mathrm{h} 12}-P_{\mathrm{r} 1}}+s\left(-u_{1}\right) \sqrt{P_{\mathrm{s} 1}-P_{\mathrm{h} 12}} .
\end{aligned}
$$

Therefore, (7) and (8) can be rewritten as

$$
\begin{aligned}
& Q_{\mathrm{h} 11}=k_{q} k_{\mathrm{i} 1} R_{\mathrm{h} 11} u_{1}, \\
& \mathrm{Q}_{\mathrm{h} 12}=k_{q} k_{\mathrm{i} 1} R_{\mathrm{h} 12} u_{1} .
\end{aligned}
$$

2.2. Model of the Control Surface. Supposing both HAs are connected rigidly to the control surface (see Figure 1), the driving forces $F_{\mathrm{dh} 1}$ and $F_{\mathrm{dh} 2}$ which are generated by the two HAs can be described by

$$
\begin{aligned}
& F_{\mathrm{dh} 1}=F_{\mathrm{h} 1}=K_{\mathrm{h} 1}\left(x_{\mathrm{h} 1}-x_{\mathrm{d}}\right), \\
& F_{\mathrm{dh} 2}=F_{\mathrm{h} 2}=K_{\mathrm{h} 2}\left(x_{\mathrm{h} 2}-x_{\mathrm{d}}\right)
\end{aligned}
$$

where $K_{\mathrm{h} 1}, K_{\mathrm{h} 2}$ are the connection stiffness and $x_{\mathrm{d}}$ is the linear displacement of the control surface. The angular displacement $\theta_{\mathrm{d}}$ can be approximately represented as a linear function of $x_{\mathrm{d}}$, then we have

$$
\theta_{\mathrm{d}}=\frac{x_{\mathrm{d}}}{r_{\mathrm{d}}}
$$


Assuming that the outputs of the HAs are summed by force, the control surface dynamics can be represented as [24]

$$
\left(F_{\mathrm{dh} 1}+F_{\mathrm{dh} 2}\right) r_{\mathrm{d}}=J_{\mathrm{d}} \ddot{\theta}_{\mathrm{d}}+\beta_{\mathrm{d}} \dot{\theta}_{\mathrm{d}}+T_{\mathrm{L}}
$$

where $r_{\mathrm{d}}$ represents the radial distance of the control surface, $J_{\mathrm{d}}$ is the moment of inertia, $\beta_{\mathrm{d}}$ is the damping coefficient, and $T_{\mathrm{L}}$ is the load torque.

2.3. State-Space Equation of the Dual Redundant Hydraulic Actuation System. Define the state variables as follows.

$$
\mathbf{x}=\left[\begin{array}{c}
x_{11}, x_{12}, x_{13} \\
x_{21}, x_{22}, x_{23}
\end{array}\right]^{T} \triangleq\left[\begin{array}{c}
x_{\mathrm{h} 1}, \dot{x}_{\mathrm{h} 1}, A_{1} P_{\mathrm{h} 11}-A_{2} P_{\mathrm{h} 12} \\
x_{\mathrm{h} 2}, \dot{x}_{\mathrm{h} 2}, A_{1} P_{\mathrm{h} 21}-A_{2} P_{\mathrm{h} 22}
\end{array}\right]^{T}
$$

According to (3)-(13), we have

$$
\begin{aligned}
& \dot{x}_{13}=f_{\mathrm{h} 11}(x) u_{1}-f_{\mathrm{h} 12}(x)-f_{\mathrm{h} 13}(x), \\
& f_{\mathrm{h} 11}(x)=\frac{A_{1} \beta_{e}}{V_{\mathrm{h} 11}} k_{q} k_{\mathrm{i} 1} R_{\mathrm{h} 11}+\frac{A_{2} \beta_{e}}{V_{\mathrm{h} 12}} k_{q} k_{\mathrm{i} 1} R_{\mathrm{h} 12}, \\
& f_{\mathrm{h} 12}(x)=\frac{A_{1} \beta_{e}}{V_{\mathrm{h} 11}}\left[A_{1} \dot{x}_{\mathrm{h} 1}+C_{\mathrm{i} 1}\left(P_{\mathrm{h} 11}-P_{\mathrm{h} 12}\right)\right] \\
& +\frac{A_{2} \beta_{e}}{V_{\mathrm{h} 12}}\left[A_{2} \dot{x}_{\mathrm{h} 1}+C_{\mathrm{i} 1}\left(P_{\mathrm{h} 11}-P_{\mathrm{h} 12}\right)\right], \\
& f_{\mathrm{h} 13}(x)=\beta_{1}\left(t-t_{\mathrm{f}}\right) C_{\mathrm{t} 1}\left(\frac{A_{1} \beta_{e}}{V_{\mathrm{h} 11}}+\frac{A_{2} \beta_{e}}{V_{\mathrm{h} 12}}\right) \\
& \cdot \sqrt{\left|P_{\mathrm{h} 11}-P_{\mathrm{h} 12}\right|} \operatorname{sgn}\left(P_{\mathrm{h} 11}-P_{\mathrm{h} 12}\right),
\end{aligned}
$$

and $\dot{x}_{23}$ can be described in a similar manner. Then, a statespace equation for the DRHAS can be written as

$$
\begin{aligned}
{\left[\begin{array}{c}
\dot{x}_{11} \\
\dot{x}_{21}
\end{array}\right]=} & {\left[\begin{array}{l}
x_{12} \\
x_{22}
\end{array}\right] } \\
{\left[\begin{array}{c}
\dot{x}_{12} \\
\dot{x}_{22}
\end{array}\right]=} & -\mathbf{H}_{1}\left[\begin{array}{l}
x_{11} \\
x_{21}
\end{array}\right]-\mathbf{H}_{2}\left[\begin{array}{l}
x_{12} \\
x_{22}
\end{array}\right]+\mathbf{H}_{3}\left[\begin{array}{l}
x_{13} \\
x_{23}
\end{array}\right] \\
& +\mathbf{H}_{4} \mathbf{x}_{\text {coupling }}-\mathbf{H}_{3} \mathbf{d} \\
{\left[\begin{array}{c}
\dot{x}_{13} \\
\dot{x}_{23}
\end{array}\right]=} & -\mathbf{F}_{2}(x)-\boldsymbol{\beta}\left(t-T_{f}\right) \mathbf{F}_{3}(x) \boldsymbol{\theta}+\mathbf{F}_{1}(x) \mathbf{u}
\end{aligned}
$$

where $\mathbf{H}_{1}=\operatorname{diag}\left(K_{\mathrm{h} 1} / m_{\mathrm{h} 1}, K_{\mathrm{h} 2} / m_{\mathrm{h} 2}\right), \mathbf{H}_{2}=\operatorname{diag}\left(B_{\mathrm{h} 1} / m_{\mathrm{h} 1}\right.$, $\left.B_{\mathrm{h} 2} / m_{\mathrm{h} 2}\right), \mathbf{H}_{3}=\operatorname{diag}\left(1 / m_{\mathrm{h} 1}, 1 / m_{\mathrm{h} 2}\right), \mathbf{H}_{4}=\operatorname{diag}\left(K_{\mathrm{h} 1} r_{\mathrm{d}} / m_{\mathrm{h} 1}\right.$, $\left.K_{\mathrm{h} 2} r_{\mathrm{d}} / m_{\mathrm{h} 2}\right), \mathbf{d}=\left[d_{1}, d_{2}\right]^{T}, \mathbf{F}_{1}(x)=\operatorname{diag}\left(f_{\mathrm{h} 11}(x), f_{\mathrm{h} 21}(x)\right)$, $\mathbf{F}_{2}(x)=\left[f_{\mathrm{h} 12}(x), f_{\mathrm{h} 22}(x)\right]^{T}, \mathbf{F}_{3}(x)=\operatorname{diag}\left(f_{\mathrm{h} 13}(x), f_{\mathrm{h} 23}(x)\right)$, $\boldsymbol{\beta}\left(t-t_{\mathrm{f}}\right)=\operatorname{diag}\left(\beta_{1}\left(t-t_{\mathrm{f}}\right), \beta_{2}\left(t-t_{\mathrm{f}}\right)\right), \boldsymbol{\theta}=\left[C_{\mathrm{t} 1}, C_{\mathrm{t} 2}\right]^{T}$ is the fault parameter vector, $\mathbf{u}=\left[u_{1}, u_{2}\right]^{T}$ is the control input vector, and $\mathbf{x}_{\text {coupling }}=\left[\theta_{\mathrm{d}}, \theta_{\mathrm{d}}\right]^{T}$ is the coupling part between two HA channels [24].

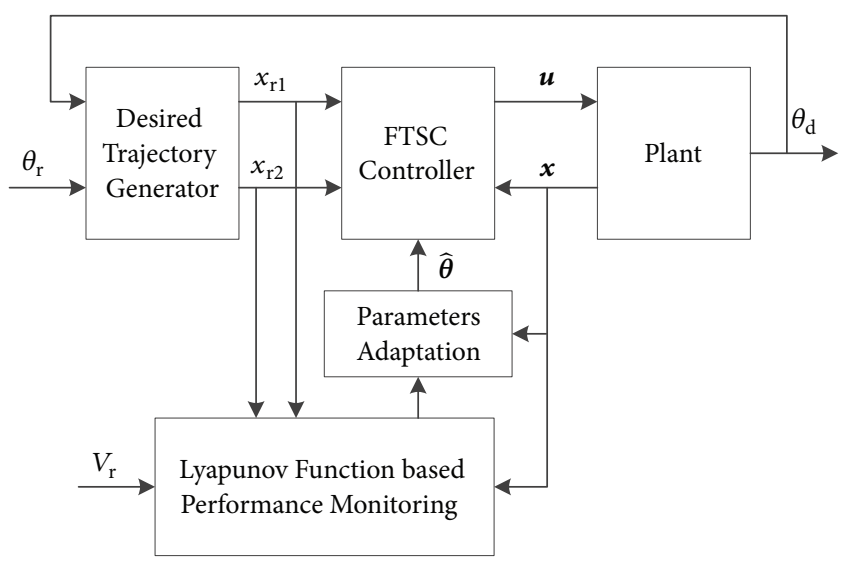

FIgURE 2: Structure diagram for the proposed FTSC scheme.

Defining the output variables as $y_{1}=\theta_{\mathrm{d}}, y_{2}=\dot{\theta}_{\mathrm{d}}$, then according to (14)-(17), the output equation can be written as

$$
\begin{aligned}
\dot{y}_{1}= & y_{2} \\
\dot{y}_{2}= & \frac{r_{\mathrm{d}}}{J_{\mathrm{d}}}\left(K_{\mathrm{h} 1} x_{\mathrm{h} 1}+K_{\mathrm{h} 2} x_{\mathrm{h} 2}\right)-\frac{r_{\mathrm{d}}^{2}}{J_{\mathrm{d}}}\left(K_{\mathrm{h} 1}+K_{\mathrm{h} 2}\right) y_{1} \\
& -\frac{\beta_{\mathrm{d}}}{J_{\mathrm{d}}} y_{2}-\frac{1}{J_{\mathrm{d}}} T_{\mathrm{L}} .
\end{aligned}
$$

Assumption 1. The chamber pressure $P_{\mathrm{h} 11}, P_{\mathrm{h} 12}$ are bounded and satisfy $P_{\mathrm{r} 1}<P_{\mathrm{h} 11}<P_{\mathrm{s} 1}, P_{\mathrm{r} 1}<P_{\mathrm{h} 12}<P_{\mathrm{s} 1}$. Similarly, the chamber pressure $P_{\mathrm{h} 21}, P_{\mathrm{h} 22}$ are bounded and satisfy $P_{\mathrm{r} 2}<$ $P_{\mathrm{h} 21}<P_{\mathrm{s} 2}, P_{\mathrm{r} 2}<P_{\mathrm{h} 22}<P_{\mathrm{s} 2}$. Meanwhile, all the state variables in (18) are bounded no matter under fault-free or faulty conditions.

Remark 2. From Assumption 1 and (10)-(11), it can be concluded that $R_{\mathrm{h} 11}>0$ and $R_{\mathrm{h} 12}>0$. Similarly, it can be derived that $R_{\mathrm{h} 21}>0$ and $R_{\mathrm{h} 22}>0$. Therefore, the inequalities $f_{\mathrm{h} 11}(x)>0$ and $f_{\mathrm{h} 21}(x)>0$ always hold and the matrix $\mathbf{F}_{1}(x)$ is reversible.

\section{Fault-Tolerant Synchronization Control Scheme}

For system (18)-(24), the purpose of this section is to design a fault-tolerant synchronization control scheme such that the output tracking error system is bounded stable under the internal leakage CMF condition and the following control performance can be guaranteed:

(a) The output deflection angle of the control surface can follow the system deflection command.

(b) The force outputs synchronization for two HAs can be maintained.

The structure of the proposed FTSC scheme is illustrated in Figure 2. To serve the control objectives, a desired trajectory generator is employed to adjust command inputs. Two reference trajectories $x_{\mathrm{r} 1}$ and $x_{\mathrm{r} 2}$ are generated for 
position tracking and for force outputs synchronization, respectively. Based on a transformed nonlinear model, an adaptive robust FTSC controller is designed by using backstepping technology. A Lyapunov function based method is used to evaluate the control performance of the closedloop system. The controller reconfigures its control action through parameters adaptation online as the degraded control performance induced by the CMF exceeds a tolerable level.

3.1. Desired Trajectory Generation. To realize the position control of the closed-loop system, a reference trajectory $x_{\mathrm{r} 1}$ is generated.

Theorem 3. The actual deflection angle $y_{1}$ can trace the deflection command $\theta_{\mathrm{r}}$ accurately if the function $f_{1}\left(x_{\mathrm{h} 1}, x_{\mathrm{h} 2}\right)=$ $K_{\mathrm{h} 1} x_{\mathrm{h} 1}+K_{\mathrm{h} 2} x_{\mathrm{h} 2}$ can trace the reference trajectory $x_{\mathrm{r} 1}$ which satisfies

$$
\begin{aligned}
x_{\mathrm{r} 1} & =\frac{J_{\mathrm{d}}}{r_{\mathrm{d}}}\left[\frac{r_{d}^{2}}{J_{\mathrm{d}}}\left(K_{\mathrm{h} 1}+K_{\mathrm{h} 2}\right) y_{1}+\frac{\beta_{d}}{J_{\mathrm{d}}} y_{2}+\frac{1}{J_{\mathrm{d}}} T_{\mathrm{L}}+\dot{\alpha}_{\mathrm{r} 1}\right. \\
& \left.-k_{2} z_{2}-z_{1}\right] .
\end{aligned}
$$

Proof. The reference trajectory $x_{\mathrm{r} 1}$ can be derived by using backstepping technique. Define two error variables as

$$
\begin{aligned}
& z_{1}=y_{1}-\theta_{\mathrm{r}}, \\
& z_{2}=y_{2}-\alpha_{\mathrm{r} 1} .
\end{aligned}
$$

Defining a Lyapunov function as $V_{1}=0.5 z_{1}^{2}$, its time derivative is

$$
\dot{V}_{1}=z_{1} \dot{z}_{1}=z_{1}\left(z_{2}+\alpha_{\mathrm{r} 1}-\dot{\theta}_{\mathrm{r}}\right)
$$

Choosing the virtue control input $\alpha_{\mathrm{r} 1}$ as

$$
\alpha_{\mathrm{r} 1}=-k_{1} z_{1}+\dot{\theta}_{\mathrm{r}}
$$

and substituting it into (27) yields

$$
\dot{V}_{1}=-k_{1} z_{1}^{2}+z_{1} z_{2}
$$

where $k_{1}$ is a positive constant.

Then choosing a Lyapunov function as $V_{2}=V_{1}+0.5 z_{2}^{2}$ and based on (24), (26), and (29), the time derivative of $V_{2}$ can be written as

$$
\begin{aligned}
\dot{V}_{2} & =\dot{V}_{1}+z_{2} \dot{z}_{2}=-k_{1} z_{1}^{2}+z_{1} z_{2} \\
& +z_{2}\left[\frac{r_{\mathrm{d}}}{J_{\mathrm{d}}}\left(K_{\mathrm{h} 1} x_{\mathrm{h} 1}+K_{\mathrm{h} 2} x_{\mathrm{h} 2}\right)-\frac{r_{d}^{2}}{J_{\mathrm{d}}}\left(K_{\mathrm{h} 1}+K_{\mathrm{h} 2}\right) y_{1}\right. \\
& \left.-\frac{\beta_{\mathrm{d}}}{J_{\mathrm{d}}} y_{2}-\frac{1}{J_{\mathrm{d}}} T_{\mathrm{L}}-\dot{\alpha}_{\mathrm{r} 1}\right] .
\end{aligned}
$$

Defining a function as $f_{1}\left(x_{\mathrm{h} 1}, x_{\mathrm{h} 2}\right)=K_{\mathrm{h} 1} x_{\mathrm{h} 1}+K_{\mathrm{h} 2} x_{\mathrm{h} 2}$ and from (30), the function $f_{1}\left(x_{\mathrm{h} 1}, x_{\mathrm{h} 2}\right)$ can be seen as a control input, and when it satisfies

$$
\begin{aligned}
& f_{1}\left(x_{\mathrm{h} 1}, x_{\mathrm{h} 2}\right)=\frac{J_{\mathrm{d}}}{r_{\mathrm{d}}}\left[\frac{r_{\mathrm{d}}^{2}}{J_{\mathrm{d}}}\left(K_{\mathrm{h} 1}+K_{\mathrm{h} 2}\right) y_{1}+\frac{\beta_{\mathrm{d}}}{J_{\mathrm{d}}} y_{2}\right. \\
& \left.+\frac{1}{J_{\mathrm{d}}} T_{\mathrm{L}}+\dot{\alpha}_{\mathrm{r} 1}-k_{2} z_{2}-z_{1}\right],
\end{aligned}
$$

(30) can be rewritten as

$$
\dot{V}_{2}=-k_{1} z_{1}^{2}-k_{2} z_{2}^{2}<0
$$

where $k_{2}$ is a positive constant.

From (32), an asymptotic tracking can be achieved; i.e., $z_{1} \longrightarrow 0$ and $y_{1} \longrightarrow \theta_{\mathrm{r}}$ as $t \longrightarrow \infty$. Therefore, Theorem 3 is proved.

In order to achieve the synchronous force outputs of two HAs and eliminate the fighting force as much as possible, a reference trajectory $x_{\mathrm{r} 2}$ is generated.

According to (14) and (15), the fighting force between two HAs can be represented as

$$
\begin{aligned}
\Delta F & =F_{\mathrm{h} 1}-F_{\mathrm{h} 2} \\
& =\left(K_{\mathrm{h} 1} x_{\mathrm{h} 1}-K_{\mathrm{h} 2} x_{\mathrm{h} 2}\right)-\left(K_{\mathrm{h} 1}-K_{\mathrm{h} 2}\right) r_{\mathrm{d}} \theta_{\mathrm{d}} .
\end{aligned}
$$

Defining a function as $f_{2}\left(x_{\mathrm{h} 1}, x_{\mathrm{h} 2}\right)=K_{\mathrm{h} 1} x_{\mathrm{h} 1}-K_{\mathrm{h} 2} x_{\mathrm{h} 2}$ and setting $x_{\mathrm{r} 2}=\left(K_{\mathrm{h} 1}-K_{\mathrm{h} 2}\right) r_{\mathrm{d}} \theta_{\mathrm{r}}$. From (33), it is evident that the fighting force $\Delta F$ will approach zero as the function $f_{2}\left(x_{\mathrm{h} 1}, x_{\mathrm{h} 2}\right)$ traces the reference trajectory $x_{\mathrm{r} 2}$ accurately.

Assumption 4. The deflection command $\theta_{\mathrm{r}}$ is $C^{5}$ continuous and bounded.

Remark 5. Noting (24), (26), (28), (31), and Assumption 4, $z_{1}$, $z_{2}, \alpha_{\mathrm{r} 1}, \dot{\alpha}_{\mathrm{r} 1}, y_{1}$, and $y_{2}$ are all bounded. Then, from (25), it is obvious that $x_{\mathrm{r} 1}$ is bounded. According to the definition of $x_{\mathrm{r} 2}$ and following Assumption 4, it is evident that $x_{\mathrm{r} 2}$ is bounded. Then, by similar analysis, it can be derived that $x_{\mathrm{r} 1}$ and $x_{\mathrm{r} 2}$ are $C^{3}$ continuous and bounded.

3.2. Model Transformation. A linear transformation $\mathbf{T}$ for the first two equations of (23) is introduced [24] and a new statespace model can be derived as

$$
\begin{aligned}
\dot{\mathbf{f}}\left(x_{11}, x_{21}, t\right)= & \mathbf{f}\left(x_{12}, x_{22}, t\right) \\
\dot{\mathbf{f}}\left(x_{12}, x_{22}, t\right)= & -\mathbf{M}_{1} \mathbf{f}\left(x_{11}, x_{21}, t\right)-\mathbf{M}_{2} \mathbf{f}\left(x_{12}, x_{22}, t\right) \\
& +\mathbf{M}_{3} \mathbf{x}_{3}+\mathbf{M}_{4} \mathbf{x}_{\text {coupling }}-\tilde{\mathbf{d}} \\
\dot{\mathbf{x}}_{3}= & -\mathbf{F}_{2}(x)-\boldsymbol{\beta}\left(t-t_{\mathrm{f}}\right) \mathbf{F}_{3}(x) \boldsymbol{\theta} \\
& +\mathbf{F}_{1}(x) \mathbf{u}
\end{aligned}
$$

where $\mathbf{T}=\left[\begin{array}{cc}K_{\mathrm{h} 1} & K_{\mathrm{h} 2} \\ K_{\mathrm{h} 1} & -K_{\mathrm{h} 2}\end{array}\right], \mathbf{f}\left(x_{11}, x_{21}, t\right)=\mathbf{T}\left[\begin{array}{l}x_{11} \\ x_{21}\end{array}\right]=\left[\begin{array}{l}f_{1}\left(x_{11}, x_{21}, t\right) \\ f_{2}\left(x_{11}, x_{21}, t\right)\end{array}\right]$, $\mathbf{x}_{3}=\left[\begin{array}{l}x_{13} \\ x_{23}\end{array}\right], \mathbf{M}_{1}=\mathbf{T H}_{1} \mathbf{T}^{-1}, \mathbf{M}_{2}=\mathbf{T} \mathbf{H}_{2} \mathbf{T}^{-1}, \mathbf{M}_{3}=\mathbf{T H} \mathbf{H}_{3}, \mathbf{M}_{4}=$ $\mathbf{T H}_{4}$ and $\widetilde{\mathbf{d}}=\mathbf{M}_{3} \mathbf{d}=\left[\widetilde{d}_{1}, \widetilde{d}_{2}\right]^{T}$. 
To facilitate using backstepping method [29] to design the FTSC controller, a new state variable $\overline{\mathbf{x}}_{3}=\mathbf{M}_{3} \mathbf{x}_{3}$ is defined and the state-space model (34) can be rewritten into the following semi-strict-feedback form [30].

$$
\begin{aligned}
\dot{\mathbf{f}}\left(x_{11}, x_{21}, t\right)= & \mathbf{f}\left(x_{12}, x_{22}, t\right) \\
\dot{\mathbf{f}}\left(x_{12}, x_{22}, t\right)= & -\mathbf{M}_{1} \mathbf{f}\left(x_{11}, x_{21}, t\right)-\mathbf{M}_{2} \mathbf{f}\left(x_{12}, x_{22}, t\right) \\
& +\overline{\mathbf{x}}_{3}+\mathbf{M}_{4} \mathbf{x}_{\text {coupling }}-\tilde{\mathbf{d}} \\
\dot{\overline{\mathbf{x}}}_{3}= & -\mathbf{M}_{3} \mathbf{F}_{2}(x)-\boldsymbol{\beta}\left(t-t_{\mathrm{f}}\right) \mathbf{M}_{3} \mathbf{F}_{3}(x) \boldsymbol{\theta} \\
& +\mathbf{M}_{3} \mathbf{F}_{1}(x) \mathbf{u}
\end{aligned}
$$

Assumption 6. The components of the model uncertainty vector $\widetilde{\mathbf{d}}$ after transformation satisfy

$$
\begin{aligned}
& \left|\tilde{d}_{1}\right| \leq \bar{d}_{1}, \\
& \left|\tilde{d}_{2}\right| \leq \bar{d}_{2}
\end{aligned}
$$

where $\bar{d}_{1}$ and $\bar{d}_{2}$ are known constants.

Assumption 7. The components of the fault parameter vector $\boldsymbol{\theta}=\left[C_{\mathrm{t} 1}, C_{\mathrm{t} 2}\right]^{T}$ satisfy

$$
\begin{aligned}
& \theta_{1 \min } \leq C_{\mathrm{t} 1} \leq \theta_{1 \max }, \\
& \theta_{2 \min } \leq C_{\mathrm{t} 2} \leq \theta_{2 \max }
\end{aligned}
$$

where $\theta_{1 \text { min }}, \theta_{1 \max }, \theta_{2 \min }$, and $\theta_{2 \max }$ are known constants. by

The effects of the internal leakage CMF can be represented

$$
\mathbf{q}_{\mathrm{f}}=\boldsymbol{\beta}\left(t-t_{\mathrm{f}}\right) \mathbf{M}_{3} \mathbf{F}_{3}(x) \boldsymbol{\theta}
$$

where $\mathbf{q}_{\mathrm{f}}=\left[q_{\mathrm{f} 1}, q_{\mathrm{f} 2}\right]^{\mathrm{T}}$.

3.3. Fault-Tolerant Synchronization Controller Design. Based on the transformed nonlinear model (35), an adaptive robust FTSC controller is developed and two control objectives should be achieved:

(1) The state variable $f_{1}\left(x_{11}, x_{21}, t\right)$ can track the reference trajectory $x_{\mathrm{r} 1}$.

(2) The state variable $f_{2}\left(x_{11}, x_{21}, t\right)$ can track the reference trajectory $x_{\mathrm{r} 2}$.

The specific design procedure is described as follows.

Step 1. Defining a vector of reference trajectory as $\mathbf{x}_{\mathrm{r}}=$ $\left[x_{\mathrm{r} 1}, x_{\mathrm{r} 2}\right]^{T}$, the tracking error vector $\mathbf{z}_{1}$ is calculated by

$$
\mathbf{z}_{1}=\left[z_{11}, z_{12}\right]^{T}=\mathbf{f}\left(x_{11}, x_{21}, t\right)-\mathbf{x}_{\mathrm{r}}
$$

Introducing a virtue control vector $\boldsymbol{\alpha}_{1}=\left[\alpha_{11}, \alpha_{21}\right]^{T}$ to stabilize $\mathbf{f}\left(x_{12}, x_{22}, t\right)$, the error vector $\mathbf{z}_{2}$ is calculated by

$$
\mathbf{z}_{2}=\left[z_{21}, z_{22}\right]^{T}=\mathbf{f}\left(x_{12}, x_{22}, t\right)-\boldsymbol{\alpha}_{1} .
$$

Defining a Lyapunov function as $V_{1}=0.5 \mathbf{z}_{1}^{T} \mathbf{z}_{1}$, its time derivative is

$$
\begin{aligned}
\dot{V}_{1} & =\mathbf{z}_{1}^{T} \dot{\mathbf{z}}_{1}=\mathbf{z}_{1}^{T}\left(\mathbf{f}\left(x_{12}, x_{22}, t\right)-\dot{\mathbf{x}}_{\mathrm{r}}\right) \\
& =\mathbf{z}_{1}^{T}\left(\mathbf{z}_{2}+\boldsymbol{\alpha}_{1}-\dot{\mathbf{x}}_{\mathrm{r}}\right)
\end{aligned}
$$

Setting $\boldsymbol{\alpha}_{1}=-\mathbf{k}_{1} \mathbf{z}_{1}+\dot{\mathbf{x}}_{\mathrm{r}}$ and substituting it into (41) yields

$$
\dot{V}_{1}=\mathbf{z}_{1}^{T} \mathbf{z}_{2}-\mathbf{z}_{1}^{T} \mathbf{k}_{1} \mathbf{z}_{1}
$$

where $\mathbf{k}_{1}=\operatorname{diag}\left(k_{11}, k_{12}\right)$ is a diagonal positive definite matrix.

Step 2. Introducing a virtual control vector $\boldsymbol{\alpha}_{2}$ to stabilize $\overline{\mathbf{x}}_{3}$, the tracking error $\mathbf{z}_{3}$ can be calculated by

$$
\mathbf{z}_{3}=\left[z_{31}, z_{32}\right]^{T}=\overline{\mathbf{x}}_{3}-\boldsymbol{\alpha}_{2} .
$$

Constructing a Lyapunov function $V_{2}=V_{1}+0.5 \mathbf{z}_{2}^{T} \mathbf{z}_{2}$, then according to (35), (40), (42), and (43), the time derivative of $V_{2}$ can be written as

$$
\begin{aligned}
\dot{V}_{2} & =\mathbf{z}_{1}^{T} \mathbf{z}_{2}-\mathbf{z}_{1}^{T} \mathbf{k}_{1} \mathbf{z}_{1}+\mathbf{z}_{2}^{T}\left[-\mathbf{M}_{1} \mathbf{f}\left(x_{11}, x_{21}, t\right)\right. \\
& -\mathbf{M}_{2} \mathbf{f}\left(x_{12}, x_{22}, t\right)+\mathbf{z}_{3}+\boldsymbol{\alpha}_{2}+\mathbf{M}_{4} \mathbf{x}_{\text {coupling }}-\tilde{\mathbf{d}} \\
& \left.-\dot{\boldsymbol{\alpha}}_{1}\right] .
\end{aligned}
$$

Choose the virtual control vector $\boldsymbol{\alpha}_{2}$ in (43) as

$$
\begin{aligned}
\boldsymbol{\alpha}_{2}= & \boldsymbol{\alpha}_{2 \mathrm{a}}+\boldsymbol{\alpha}_{2 \mathrm{~s}} \\
\boldsymbol{\alpha}_{2 \mathrm{a}}= & -\mathbf{z}_{1}+\mathbf{M}_{1} \mathbf{f}\left(x_{11}, x_{21}, t\right)+\mathbf{M}_{2} \mathbf{f}\left(x_{12}, x_{22}, t\right) \\
& -\mathbf{M}_{4} \mathbf{x}_{\text {coupling }}+\dot{\boldsymbol{\alpha}}_{1}, \\
\boldsymbol{\alpha}_{2 \mathrm{~s}}= & \boldsymbol{\alpha}_{2 \mathrm{~s} 1}+\boldsymbol{\alpha}_{2 \mathrm{~s} 2} \\
\boldsymbol{\alpha}_{2 \mathrm{~s} 1}= & -\mathbf{k}_{2 \mathrm{~s} 1} \mathbf{z}_{2}
\end{aligned}
$$

where $\boldsymbol{\alpha}_{2 \mathrm{a}}$ is an adjustable model compensation term, $\boldsymbol{\alpha}_{2 \mathrm{~s} 1}$ is a nominal stabilizing feedback, $\boldsymbol{\alpha}_{2 \mathrm{~s} 2}$ is an additional feedback term to tackle the model uncertainties, and $\mathbf{k}_{2 \mathrm{~s} 1}=$ $\operatorname{diag}\left(k_{2 s 11}, k_{2 s 12}\right)$ is a diagonal positive definite matrix.

The item $\boldsymbol{\alpha}_{2 \mathrm{~s} 2}=\left[\alpha_{2 \mathrm{~s} 21}, \alpha_{2 \mathrm{~s} 22}\right]^{\mathrm{T}}$ in (45) should satisfy the following conditions:

(i) $z_{21}\left[\alpha_{2 \mathrm{~s} 21}-\tilde{d}_{1}\right] \leq \varepsilon_{1}$ and $z_{22}\left[\alpha_{2 \mathrm{~s} 22}-\tilde{d}_{2}\right] \leq \varepsilon_{2}$,

(ii) $z_{21} \alpha_{2 \mathrm{~s} 21} \leq 0$ and $z_{22} \alpha_{2 \mathrm{~s} 22} \leq 0$

where $\varepsilon_{1}$ and $\varepsilon_{2}$ are positive design parameters. In condition (i), $\alpha_{2 \mathrm{~s} 21}$ and $\alpha_{2 \mathrm{~s} 22}$ are used to tackle the model uncertainties $\widetilde{d}_{1}$ and $\widetilde{d}_{2}$ in two HA channels, respectively. Condition (ii) is to ensure that the control items $\alpha_{2 \mathrm{~s} 21}$ and $\alpha_{2 \mathrm{~s} 22}$ are dissipating in nature without affecting the functionality of the control item $\boldsymbol{\alpha}_{2 \mathrm{a}}$.

Remark 8 (see [30]). To meet the conditions of (46), we can choose

$$
\boldsymbol{\alpha}_{2 \mathrm{~s} 2}=\left[\alpha_{2 \mathrm{~s} 21}, \alpha_{2 \mathrm{~s} 22}\right]^{T}=\left[-\frac{h_{21}}{4 \varepsilon_{1}} z_{21},-\frac{h_{22}}{4 \varepsilon_{2}} z_{22}\right]^{T}
$$


where $h_{21}$ and $h_{22}$ are positive design parameters and satisfy

$$
\begin{aligned}
& h_{21} \geq \bar{d}_{1}^{2}, \\
& h_{22} \geq \bar{d}_{2}^{2} .
\end{aligned}
$$

Remark 9. From condition (i) of (46), it can be derived that

$$
\mathbf{z}_{2}^{T}\left[\boldsymbol{\alpha}_{2 \mathrm{~s} 2}-\tilde{\mathbf{d}}\right] \leq \varepsilon
$$

where $\varepsilon=\varepsilon_{1}+\varepsilon_{2}$. Note that the smaller the value of $\varepsilon$, the better the robust control performance can be achieved.

Substituting (45) into (44) yields

$$
\dot{V}_{2}=-\mathbf{z}_{1}^{T} \mathbf{k}_{1} \mathbf{z}_{1}-\mathbf{z}_{2}^{T} \mathbf{k}_{2 \mathrm{~s} 1} \mathbf{z}_{2}+\mathbf{z}_{2}^{T}\left(\boldsymbol{\alpha}_{2 \mathrm{~s} 2}-\tilde{\mathbf{d}}\right)+\mathbf{z}_{2}^{T} \mathbf{z}_{3} .
$$

Step 3. Similarly, constructing a Lyapunov function $V_{3}=$ $V_{2}+0.5 \mathbf{z}_{3}^{T} \mathbf{z}_{3}$, then according to (35), (43), and (50), the time derivative of $V_{3}$ can be calculated by

$$
\begin{aligned}
\dot{V}_{3} & =\dot{V}_{2}+\mathbf{z}_{3}^{T} \dot{\mathbf{z}}_{3}=-\mathbf{z}_{1}^{T} \mathbf{k}_{1} \mathbf{z}_{1}-\mathbf{z}_{2}^{T} \mathbf{k}_{2 \mathrm{~s} 1} \mathbf{z}_{2}+\mathbf{z}_{2}^{T}\left(\boldsymbol{\alpha}_{2 \mathrm{~s} 2}-\tilde{\mathbf{d}}\right) \\
& +\mathbf{z}_{2}^{T} \mathbf{z}_{3}+\mathbf{z}_{3}^{T}\left[-\mathbf{M}_{3} \mathbf{F}_{2}(x)-\boldsymbol{\beta}\left(t-t_{\mathrm{f}}\right) \mathbf{M}_{3} \mathbf{F}_{3}(x) \boldsymbol{\theta}\right. \\
& \left.+\mathbf{M}_{3} \mathbf{F}_{1}(x) \mathbf{u}-\dot{\boldsymbol{\alpha}}_{2}\right] .
\end{aligned}
$$

The control law $\mathbf{u}$ can be described as follows:

$$
\begin{aligned}
& \mathbf{u}=\mathbf{u}_{\mathrm{a}}+\mathbf{u}_{\mathrm{s}} \\
& \mathbf{u}_{\mathrm{a}}=\mathbf{F}_{1}^{-1}(x)\left[\mathbf{F}_{2}(x)+\mathbf{F}_{3}(x) \hat{\boldsymbol{\theta}}+\mathbf{M}_{3}^{-1}\left(\dot{\boldsymbol{\alpha}}_{2}-\mathbf{z}_{2}\right)\right] \\
& \mathbf{u}_{\mathrm{s}}=\mathbf{F}_{1}^{-1}(x) \mathbf{M}_{3}^{-1}\left(\mathbf{u}_{\mathrm{s} 1}+\mathbf{u}_{\mathrm{s} 2}\right) \\
& \mathbf{u}_{\mathrm{s} 1}=-\mathbf{k}_{3 \mathrm{~s} 1} \mathbf{z}_{3}
\end{aligned}
$$

where $\widehat{\boldsymbol{\theta}}$ is an estimation of $\boldsymbol{\theta}, \mathbf{u}_{\mathrm{a}}$ is an adjustable model compensation term, $\mathbf{u}_{\mathrm{s} 1}$ is a nominal stabilizing feedback, $\mathbf{u}_{\mathrm{s} 2}$ is a nonlinear robust control law to tolerate the effects of the slight internal leakage CMF, and $\mathbf{k}_{3 \mathrm{~s} 1}=\operatorname{diag}\left(k_{3 \mathrm{~s} 11}, k_{3 \mathrm{~s} 12}\right)$ is a diagonal positive definite matrix.

Remark 10. Under no leakage or slight internal leakage CMF condition, the proposed FTSC control law (52) without parameters adaptation is actually a nonlinear robust synchronization control (NRSC) law.

From (38), the effect of the slight internal leakage CMF for each HA channel, which can be tolerated by the robust control law $\mathbf{u}_{\mathrm{s} 2}$, should satisfy

$$
\begin{aligned}
& \left|q_{\mathrm{f} 1}\right| \leq \bar{q}_{\mathrm{f} 1}, \\
& \left|q_{\mathrm{f} 2}\right| \leq \bar{q}_{\mathrm{f} 2}
\end{aligned}
$$

where $\bar{q}_{\mathrm{f} 1}, \bar{q}_{\mathrm{f} 2}$ are predefined constants and represent the tolerable level of the slight internal leakage for $\mathrm{HA}_{1}$ and $\mathrm{HA}_{2}$, respectively.

Subsequently, the robust control law $\mathbf{u}_{\mathrm{s} 2}=\left[u_{\mathrm{s} 21}, u_{\mathrm{s} 22}\right]^{\mathrm{T}}$ in (52) should satisfy the following conditions.

(i) $z_{31}\left[u_{\mathrm{s} 21}-q_{\mathrm{f} 1}\right] \leq \xi_{1}$ and $z_{32}\left[u_{\mathrm{s} 22}-q_{\mathrm{f} 2}\right] \leq \xi_{2}$,

(ii) $z_{31} u_{\mathrm{s} 21} \leq 0$ and $z_{32} u_{\mathrm{s} 22} \leq 0$
In condition (i) of (54), $u_{\mathrm{s} 21}$ and $u_{\mathrm{s} 22}$ are robust control laws to tolerate the effects of the slight internal leakage $q_{\mathrm{f} 1}$ and $q_{\mathrm{f} 2}$ in two HA channels, respectively, and the control accuracy for them is quantified by the positive design parameters $\xi_{1}$ and $\xi_{2}$, respectively. The condition (ii) of (54) is to ensure that the control law $\mathbf{u}_{\mathrm{s} 2}$ is damping without affecting the functionality of $\mathbf{u}_{\mathrm{a}}$.

Remark 11. The control law $\mathbf{u}_{\mathrm{s} 2}$ is chosen as

$$
\mathbf{u}_{\mathrm{s} 2}=\left[u_{\mathrm{s} 21}, u_{\mathrm{s} 22}\right]^{T}=\left[-\frac{h_{31}}{4 \xi_{1}} z_{31},-\frac{h_{32}}{4 \xi_{2}} z_{32}\right]^{T}
$$

where $h_{31}$ and $h_{32}$ are positive design parameters which satisfy

$$
\begin{aligned}
& h_{31} \geq \bar{q}_{\mathrm{f} 1}^{2}, \\
& h_{32} \geq \bar{q}_{\mathrm{f} 2}^{2},
\end{aligned}
$$

and it is easy to verify that the control law (55) satisfies both the conditions of (54).

Remark 12. According to the condition (i) of (54), it can be derived that

$$
\begin{array}{r}
\mathbf{z}_{3}^{T}\left[\mathbf{u}_{\mathrm{s} 2}-\mathbf{q}_{\mathrm{f}}\right] \leq \xi, \\
\mathbf{z}_{3}^{T} \mathbf{u}_{\mathrm{s} 2} \leq 0
\end{array}
$$

with $\xi=\xi_{1}+\xi_{2}$. Similarly, the smaller the value of $\xi$, the better the robust control performance that can be achieved.

Then substituting (52) into (51) yields

$$
\begin{aligned}
\dot{V}_{3} & =-\mathbf{z}_{1}^{T} \mathbf{k}_{1} \mathbf{z}_{1}-\mathbf{z}_{2}^{T} \mathbf{k}_{2 \mathrm{~s} 1} \mathbf{z}_{2}+\mathbf{z}_{2}^{T}\left(\boldsymbol{\alpha}_{2 \mathrm{~s} 2}-\tilde{\mathbf{d}}\right)+\mathbf{z}_{2}^{T} \mathbf{z}_{3} \\
& +\mathbf{z}_{3}^{T}\left[-\boldsymbol{\beta}\left(t-t_{\mathrm{f}}\right) \mathbf{M}_{3} \mathbf{F}_{3}(x) \boldsymbol{\theta}+\mathbf{M}_{3} \mathbf{F}_{3}(x) \widehat{\boldsymbol{\theta}}-\mathbf{k}_{3 \mathrm{~s} 1} \mathbf{z}_{3}\right. \\
& \left.+\mathbf{u}_{\mathrm{s} 2}-\mathbf{z}_{2}\right] .
\end{aligned}
$$

Theorem 13. For the model uncertainties satisfying inequality (36) or/and the slight internal leakage CMF occurring in the DRHAS fulfilling inequality (53), the robust control law (52) without parameters adaptation (i.e., $\hat{\boldsymbol{\theta}}=\mathbf{0}$ ) can guarantee the following:

(a) All signals are bounded and the Lyapunov function $V_{3}$ is bounded by

$$
V_{3}(t) \leq V_{\mathrm{r}}(t)
$$

where

$$
V_{\mathrm{r}}(t)=\exp (-\lambda t) V_{3}(0)+\frac{\mu}{\lambda}[1-\exp (-\lambda t)],
$$

and $\lambda=-2 \min \left(k_{11}, k_{12}, k_{2 s 11}, k_{2 s 12}, k_{3 s 11}, k_{3 s 12}\right), \mu=\varepsilon+\xi$, and $V_{3}(0)$ is the initial value of $V_{3}$.

(b) If there are no model uncertainties and internal leakage CMF after a finite time $t_{0}$ (i.e., $\widetilde{\mathbf{d}}=\mathbf{0}, \mathbf{q}_{\mathrm{f}}=\mathbf{0}, \forall t \geq t_{0}$ ), then, except for the results in (a) of Theorem 13, zero final tracking error can also be achieved (i.e., $\mathbf{z}_{1} \longrightarrow \mathbf{0}$ as $t \longrightarrow \infty$ ). 
Proof. Substituting (38), (49), and (57) into (58) yields

$$
\begin{aligned}
\dot{V}_{3}= & -\mathbf{z}_{1}^{T} \mathbf{k}_{1} \mathbf{z}_{1}-\mathbf{z}_{2}^{T} \mathbf{k}_{2 \mathrm{~s} 1} \mathbf{z}_{2}-\mathbf{z}_{3}^{T} \mathbf{k}_{3 \mathrm{~s} 1} \mathbf{z}_{3}+\mathbf{z}_{2}^{T}\left(\boldsymbol{\alpha}_{2 \mathrm{~s} 2}-\tilde{\mathbf{d}}\right) \\
& +\mathbf{z}_{3}^{T}\left(\mathbf{u}_{\mathrm{s} 2}-\mathbf{q}_{\mathrm{f}}\right) \\
\leq & -\mathbf{z}_{1}^{T} \mathbf{k}_{1} \mathbf{z}_{1}-\mathbf{z}_{2}^{T} \mathbf{k}_{2 \mathrm{~s} 1} \mathbf{z}_{2}-\mathbf{z}_{3}^{T} \mathbf{k}_{3 \mathrm{~s} 1} \mathbf{z}_{3}+\varepsilon+\xi \\
\leq & -2 \min \left(k_{11}, k_{22}, k_{2 s 11}, k_{2 s 12}, k_{3 s 11}, k_{3 s 12}\right) V_{3}+\mu
\end{aligned}
$$

which leads to inequality (59) and (60). Therefore, $\mathbf{z}_{1}, \mathbf{z}_{2}$, and $\mathbf{z}_{3}$ are bounded. Since $\mathbf{x}_{\mathrm{r}}$ is $C^{3}$ continous and bounded, from (39)-(41), $\mathbf{f}\left(x_{11}, x_{21}, t\right), \mathbf{f}\left(x_{12}, x_{22}, t\right), \boldsymbol{\alpha}_{1}, \dot{\mathbf{z}}_{1}$, and $\dot{\boldsymbol{\alpha}}_{1}$ are bounded. As $y_{1}$ and $y_{2}$ are bounded, $\mathbf{x}_{\text {coupling }}$ and $\dot{\mathbf{x}}_{\text {coupling }}$ are bounded. Then, from (45) and (43), $\boldsymbol{\alpha}_{2}$ and $\overline{\mathbf{x}}_{3}$ are bounded. Noting Assumption 6, (35), and (39), $\dot{\mathbf{f}}\left(x_{12}, x_{22}, t\right), \ddot{\mathbf{z}}_{1}$, and $\ddot{\boldsymbol{\alpha}}_{1}$ are bounded. Hence, from (45), $\dot{\boldsymbol{\alpha}}_{2}$ is bounded. Then, noting Assumption 1 and (52), the control input $\mathbf{u}$ is bounded. Therefore, the (a) of Theorem 13 is proved.

Furthermore, when $\tilde{\mathbf{d}}=\mathbf{0}, \mathbf{q}_{\mathrm{f}}=\mathbf{0}$ after a finite time $t_{0}$, (61) can be rewritten as

$$
\begin{aligned}
\dot{V}_{3}= & -\mathbf{z}_{1}^{T} \mathbf{k}_{1} \mathbf{z}_{1}-\mathbf{z}_{2}^{T} \mathbf{k}_{2 \mathrm{~s} 1} \mathbf{z}_{2}-\mathbf{z}_{3}^{T} \mathbf{k}_{3 \mathrm{~s} 1} \mathbf{z}_{3}+\mathbf{z}_{2}^{T} \boldsymbol{\alpha}_{2 \mathrm{~s} 2} \\
& +\mathbf{z}_{3}^{T} \mathbf{u}_{\mathrm{s} 2},
\end{aligned}
$$

and then following condition (ii) of (46) and (54), we have

$$
\dot{V}_{3} \leq-\mathbf{z}_{1}^{T} \mathbf{k}_{1} \mathbf{z}_{1}-\mathbf{z}_{2}^{T} \mathbf{k}_{2 \mathrm{~s} 1} \mathbf{z}_{2}-\mathbf{z}_{3}^{T} \mathbf{k}_{3 \mathrm{~s} 1} \mathbf{z}_{3} \leq-\lambda V_{3} .
$$

Hence, the (b) of Theorem 13 is proved.

Remark 14. If a moderate or severe internal leakage CMF occurs, inequality (53) will be violated which means that the control law (52) without fault parameter adaptation cannot tolerant the CMF any more. Meanwhile, the performance of the closed-loop system will deteriorate immediately, followed by a violation of inequality (59). Therefore, the quadratic Lyapunov function $V_{3}(t)$ is adopted as a performance indicator.

Remark 15. The function $V_{\mathrm{r}}(t)$ is used as a tolerable performance degradation level. As shown in (60), the maximum value of $V_{\mathrm{r}}(t)$ can be freely chosen by adjusting the controller parameters $\mu$ and $\lambda$. Note that the smaller the value of $\mu$ or the larger the value of $\lambda$, the better the transient performance that can be guaranteed.

Remark 16. Through online monitoring of the value of $V_{3}(t)$ and comparing it with the value of $V_{\mathrm{r}}(t)$, a moderate or severe internal leakage CMF can be indicated as inequality (59) is violated over a period of time, and a condition-based maintenance operation can be performed to take the place of the scheduled maintenance, which will effectively reduce the maintenance costs.

If the performance indicator exceeds a tolerable performance degradation level, the controller reconfigures its control actions through controller parameter adaptation.

$$
\text { As } t-t_{\mathrm{f}} \longrightarrow \infty, \boldsymbol{\beta}\left(t-t_{\mathrm{f}}\right) \mathbf{M}_{3} \mathbf{F}_{3}(x) \boldsymbol{\theta} \longrightarrow \mathbf{M}_{3} \mathbf{F}_{3}(x) \boldsymbol{\theta},
$$
can be rewritten as

$$
\begin{aligned}
\dot{V}_{3}= & -\mathbf{z}_{1}^{T} \mathbf{k}_{1} \mathbf{z}_{1}-\mathbf{z}_{2}^{T} \mathbf{k}_{2 \mathrm{~s} 1} \mathbf{z}_{2}+\mathbf{z}_{2}^{T}\left(\boldsymbol{\alpha}_{2 \mathrm{~s} 2}-\tilde{\mathbf{d}}\right)+\mathbf{z}_{3}^{T} \mathbf{u}_{\mathrm{s} 2} \\
& -\mathbf{z}_{3}^{T} \mathbf{k}_{3 \mathrm{~s} 1} \mathbf{z}_{3}-\mathbf{z}_{3}^{T} \mathbf{M}_{3} \mathbf{F}_{3}(x) \tilde{\boldsymbol{\theta}}
\end{aligned}
$$

where $\widetilde{\boldsymbol{\theta}}=\boldsymbol{\theta}-\widehat{\boldsymbol{\theta}}$.

Furthermore, construct a Lyapunov function shown as follows:

$$
V=V_{3}+0.5 \widetilde{\boldsymbol{\theta}}^{T} \boldsymbol{\Gamma}^{-1} \widetilde{\boldsymbol{\theta}}
$$

where the learning rate matrix $\boldsymbol{\Gamma}=\operatorname{diag}\left(\Gamma_{1}, \Gamma_{2}\right)$ is a diagonal positive definite matrix and the time derivative of $V$ is equivalent to

$$
\begin{aligned}
\dot{V}= & \dot{V}_{3}+\widetilde{\boldsymbol{\theta}}^{T} \boldsymbol{\Gamma}^{-1} \dot{\widetilde{\boldsymbol{\theta}}} \\
= & -\mathbf{z}_{1}^{T} \mathbf{k}_{1} \mathbf{z}_{1}-\mathbf{z}_{2}^{T} \mathbf{k}_{2 \mathrm{~s} 1} \mathbf{z}_{2}-\mathbf{z}_{3}^{T} \mathbf{k}_{3 \mathrm{~s} 1} \mathbf{z}_{3}+\varepsilon+\mathbf{z}_{3}^{T} \mathbf{u}_{\mathrm{s} 2} \\
& -\tilde{\boldsymbol{\theta}}^{T} \boldsymbol{\Gamma}^{-1}\left[\boldsymbol{\Gamma} \mathbf{F}_{3}^{T}(x) \mathbf{M}_{3}^{T} \mathbf{z}_{3}+\dot{\hat{\boldsymbol{\theta}}}\right] .
\end{aligned}
$$

From the above equation, an online updating law for estimation of internal leakage CMF can be derived by using the discontinuous projection mapping [30].

$$
\dot{\hat{\boldsymbol{\theta}}}= \begin{cases}0 & V_{3}(t) \leq V_{\mathrm{r}}(t) \\ \operatorname{Proj}_{\widehat{\boldsymbol{\theta}}}(\boldsymbol{\sigma}) & V_{3}(t)>V_{\mathrm{r}}(t)\end{cases}
$$

where $\boldsymbol{\sigma}=-\boldsymbol{\Gamma} \mathbf{F}_{3}^{T}(x) \mathbf{M}_{3}^{T} \mathbf{z}_{3}$ and the discontinuous projection mapping is defined as follows:

$$
\operatorname{Proj}_{\widehat{\boldsymbol{\theta}}}(\boldsymbol{\sigma})= \begin{cases}0 & \text { if } \widehat{\boldsymbol{\theta}}=\boldsymbol{\theta}_{\text {max }} \text { and } \boldsymbol{\sigma}>\mathbf{0} \\ 0 & \text { if } \widehat{\boldsymbol{\theta}}=\boldsymbol{\theta}_{\min } \text { and } \boldsymbol{\sigma}<\mathbf{0} \\ \boldsymbol{\sigma} & \text { otherwise, }\end{cases}
$$

which guarantees that the parameters adaptation process has the following properties:

$$
\begin{aligned}
& \text { P1. } \widehat{\boldsymbol{\theta}} \in \Omega_{\widehat{\boldsymbol{\theta}}}=\left\{\widehat{\boldsymbol{\theta}}: \widehat{\boldsymbol{\theta}}_{\min } \leq \widehat{\boldsymbol{\theta}} \leq \widehat{\boldsymbol{\theta}}_{\max }\right\}, \\
& \text { P2. } \widetilde{\boldsymbol{\theta}}^{T} \boldsymbol{\Gamma}^{-1}\left(\operatorname{Proj}_{\widehat{\boldsymbol{\theta}}}(\boldsymbol{\sigma})-\boldsymbol{\sigma}\right) \leq 0, \quad \forall \boldsymbol{\sigma} .
\end{aligned}
$$

Theorem 17. For the DRHAS suffering from moderate or severe internal leakage CMF which violates inequality (53), the control law (52) combined with the parameter adaptation law (67) can guarantee that the closed-loop control system gradually recover its performance if the following persistent excitation (PE) condition is satisfied:

$$
\begin{aligned}
\exists T, \delta & >0 \\
\text { s.t. } \int_{t}^{t+T} \varphi(v) \varphi(v)^{T} d v & \geq \delta \mathbf{I}, \quad \forall t
\end{aligned}
$$

with $\varphi(v)=\mathbf{F}_{3}^{T}(x) \mathbf{M}_{3}^{T}$. 
TABLE 1: Simulation parameters of the DRHAS $[13,24]$.

\begin{tabular}{|c|c|c|c|c|}
\hline Component & Parameter & Value (Unit) & Parameter & Value (Unit) \\
\hline EHSV & EHSV gain $k_{\mathrm{i} 1}, k_{\mathrm{i} 2}$ & $3.04 \times 10^{-3}(\mathrm{~m} / \mathrm{A})$ & Flow rate gain $k_{q}$ & $\begin{array}{c}7.5 \times 10^{-5} \\
\left(\mathrm{~m}^{2} / \mathrm{s} / \mathrm{pa}^{1 / 2}\right)\end{array}$ \\
\hline Cylinder & $\begin{array}{c}\text { Piston mass } m_{\mathrm{h} 1}, m_{\mathrm{h} 1} \\
\text { Piston area (passive chamber) } A_{2} \\
\text { Damping coefficient } B_{\mathrm{h} 1}, B_{\mathrm{h} 2} \\
\text { Initial volume (passive chamber) } V_{20}\end{array}$ & $\begin{array}{c}55(\mathrm{~kg}) \\
1.47 \times 10^{-3}\left(\mathrm{~m}^{2}\right) \\
1 \times 10^{4}(\mathrm{Ns} / \mathrm{m}) \\
0.735 \times 10^{-4}\left(\mathrm{~m}^{3}\right) \\
\end{array}$ & $\begin{array}{c}\text { Piston area (active chamber) } A_{1} \\
\text { Effective oil bulk modulus } \beta_{e} \\
\text { Initial volume (active chamber) } V_{10} \\
\text { Normal internal leakage coefficient } C_{\mathrm{i} 1}, C_{\mathrm{i} 2}\end{array}$ & $\begin{array}{c}1.47 \times 10^{-3}\left(\mathrm{~m}^{2}\right) \\
800(\mathrm{MPa}) \\
0.735 \times 10^{-4}\left(\mathrm{~m}^{3}\right) \\
1 \times 10^{-12}\left(\mathrm{~m}^{3} / \mathrm{s} / \mathrm{pa}\right) \\
\end{array}$ \\
\hline Control Surface & $\begin{array}{c}\text { Connection stiffness } K_{\mathrm{h} 1}, K_{\mathrm{h} 2} \\
\text { Moment of inertia } J_{\mathrm{d}} \\
\text { Elastic load coefficient } K_{\mathrm{d}}\end{array}$ & $\begin{array}{c}1 \times 10^{8}(\mathrm{~N} / \mathrm{m}) \\
13.5\left(\mathrm{kgm}^{2}\right) \\
9.14 \times 10^{5}(\mathrm{~N} / \mathrm{m}) \\
\end{array}$ & $\begin{array}{c}\text { Radial distance } r_{\mathrm{d}} \\
\text { Damping coefficient } \beta_{\mathrm{d}}\end{array}$ & $\begin{array}{c}0.15(\mathrm{~m}) \\
51.75(\mathrm{Nms})\end{array}$ \\
\hline Power Supply & Oil supply pressure $P_{\mathrm{s} 1}, P_{\mathrm{s} 2}$ & $28(\mathrm{MPa})$ & Oil reservoir pressure $P_{\mathrm{r} 1}, P_{\mathrm{r} 2}$ & $0(\mathrm{MPa})$ \\
\hline
\end{tabular}

TABLE 2: Parameters of the control schemes.

\begin{tabular}{|c|c|c|c|c|}
\hline Scheme & Parameter & Value & Parameter & Value \\
\hline \multirow{6}{*}{ FTSC /NRSC } & $k_{1}$ & 300 & $k_{2}$ & 300 \\
\hline & $\mathbf{k}_{1}$ & $\operatorname{diag}(1000,1000)$ & $\mathbf{k}_{2 s 1}$ & $\operatorname{diag}(1000,1000)$ \\
\hline & $\mathbf{k}_{3 \mathrm{~s} 1}$ & $\operatorname{diag}(1000,1000)$ & $h_{21}, h_{22}$ & $3.4 \times 10^{18}$ \\
\hline & $\varepsilon_{1}, \varepsilon_{2}$ & $1.0 \times 10^{14}$ & $h_{31}, h_{32}$ & $2.5 \times 10^{23}$ \\
\hline & $\xi_{1}, \xi_{2}$ & $1.0 \times 10^{21}$ & $\bar{d}_{1}, \bar{d}_{2}$ & $1.8 \times 10^{9}$ \\
\hline & $\begin{array}{c}\bar{q}_{\mathrm{f} 1}, \bar{q}_{\mathrm{f} 2} \\
\boldsymbol{\theta}_{\min }\end{array}$ & $\begin{array}{c}4.5 \times 10^{11} \\
{[0,0]^{T}}\end{array}$ & $\boldsymbol{\theta}_{\max }$ & {$\left[5.0 \times 10^{-6}, 5.0 \times 10^{-6}\right]^{T}$} \\
\hline FTSC & $\Gamma_{1}, \Gamma_{2}$ & $1.0 \times 10^{-37}$ & & \\
\hline \multirow{2}{*}{ PID } & $k_{\mathrm{p} 1}, k_{\mathrm{p} 2}$ & 90 & $k_{\mathrm{i} 1}, k_{\mathrm{i} 2}$ & 0 \\
\hline & $k_{\mathrm{d} 1}, k_{\mathrm{d} 2}$ & 0 & & \\
\hline
\end{tabular}

Proof. In this situation, the third equation of (35) can be rewritten as

$$
\dot{\overline{\mathbf{x}}}_{3}=-\mathbf{M}_{3} \mathbf{F}_{2}(x)-\mathbf{M}_{3} \mathbf{F}_{3}(x) \boldsymbol{\theta}+\mathbf{M}_{3} \mathbf{F}_{1}(x) \mathbf{u} .
$$

Then, the time derivative of $\mathbf{z}_{3}$ is equal to

$$
\dot{\mathbf{z}}_{3}=\dot{\overline{\mathbf{x}}}_{3}-\dot{\boldsymbol{\alpha}}_{2}=-\mathbf{z}_{2}-\mathbf{k}_{3 \mathrm{~s} 1} \mathbf{z}_{3}+\mathbf{u}_{\mathrm{s} 2}-\boldsymbol{\varphi}^{T} \widetilde{\boldsymbol{\theta}}
$$

Note that there is no unknown disturbance in (72) and the PE condition (70) can be easily satisfied as the integral term is a diagonal positive definite matrix. Therefore, the CMF estimation $\widehat{\boldsymbol{\theta}}$ will converge to its real value (i.e., $\widetilde{\boldsymbol{\theta}} \longrightarrow \mathbf{0}$ as $t \longrightarrow \infty)$. Thus, (64) can be rewritten as

$$
\begin{aligned}
\dot{V}_{3}= & -\mathbf{z}_{1}^{T} \mathbf{k}_{1} \mathbf{z}_{1}-\mathbf{z}_{2}^{T} \mathbf{k}_{2 \mathrm{~s} 1} \mathbf{z}_{2}+\mathbf{z}_{2}^{T}\left(\boldsymbol{\alpha}_{2 \mathrm{~s} 2}-\tilde{\mathbf{d}}\right)+\mathbf{z}_{3}^{T} \mathbf{u}_{\mathrm{s} 2} \\
& -\mathbf{z}_{3}^{T} \mathbf{k}_{3 \mathrm{~s} 1} \mathbf{z}_{3} \\
\leq & -\mathbf{z}_{1}^{T} \mathbf{k}_{1} \mathbf{z}_{1}-\mathbf{z}_{2}^{T} \mathbf{k}_{2 \mathrm{~s} 1} \mathbf{z}_{2}-\mathbf{z}_{3}^{T} \mathbf{k}_{3 \mathrm{~s} 1} \mathbf{z}_{3}+\varepsilon+\mathbf{z}_{3}^{T} \mathbf{u}_{\mathrm{s} 2} \\
\leq & \lambda V_{3}+\varepsilon
\end{aligned}
$$

which leads to the same result as (59). If there are no model uncertainties after a finite time $t_{1}$ (i.e., $\widetilde{\mathbf{d}}=\mathbf{0}, \mathbf{q}_{\mathrm{f}}=\mathbf{0}, \forall t \geq t_{1}$ ), the same result as (63) can be obtained. Thus, Theorem 17 is proved.

\section{Simulation Results}

To illustrate the effectiveness of the proposed FTSC scheme, a model of a DRHAS is established in the MATLAB/Simulink environment. Simulation parameters of the model are given in Table 1.

A comprehensive performance evaluation regarding the proposed FTSC scheme is performed in comparison with the other two schemes, i.e., the classical PID and the NRSC. Moreover, the following two scenarios are considered:

(a) Scenario S1: A severe internal leakage CMF which has different effects (i.e., different magnitudes and evolution speeds) on two channels occurs in the DRHAS. Specifically, at $t_{\mathrm{f}}=7 \mathrm{~s}$, a severe internal leakage fault with $C_{\mathrm{t} 1}=5 \times$ $10^{-7}\left(\mathrm{~m}^{3} / \mathrm{s} / \mathrm{pa}\right), \mu_{1}=10$ occurs in $\mathrm{HA}_{1}$ and a severe internal leakage fault with $C_{\mathrm{t} 2}=1 \times 10^{-7}\left(\mathrm{~m}^{3} / \mathrm{s} / \mathrm{pa}\right), \mu_{2}=0.5$ occurs in $\mathrm{HA}_{2}$ due to a common cause.

(b) Scenario S2: A slight internal leakage CMF occurs in the DRHAS. Specifically, at $t_{\mathrm{f}}=7 \mathrm{~s}$, a slight internal leakage with $C_{\mathrm{t} 1}=1 \times 10^{-9}\left(\mathrm{~m}^{3} / \mathrm{s} / \mathrm{pa}\right), \mu_{1}=5$ occurs in $\mathrm{HA}_{1}$ and a slight internal leakage with $C_{\mathrm{t} 2}=0.5 \times 10^{-9}\left(\mathrm{~m}^{3} / \mathrm{s} / \mathrm{pa}\right), \mu_{2}=10$ occurs in $\mathrm{HA}_{2}$ due to a common cause.

The parameters for the control schemes are shown in Table 2. In addition, $\theta_{\mathrm{r}}=\arctan (0.2 \sin (2 \pi t))\left[1-\exp \left(-0.1 t^{3}\right)\right]$ is used as the system deflection command to fulfill Assumption 4. An elastic load $F_{\mathrm{L}}=K_{\mathrm{d}} x_{\mathrm{d}}$ is used to simulate the air loads acting on the control surface and the unknown model uncertainties $d_{1}$ and $d_{2}$ in two HAs are as follows: 
TABLE 3: Maximum tracking error for three control schemes under different scenarios.

\begin{tabular}{|c|c|c|c|c|c|}
\hline \multirow{2}{*}{$\begin{array}{l}\text { Maximum } \\
\text { tracking error } \\
(\mathrm{rad})\end{array}$} & \multirow[b]{2}{*}{$\begin{array}{l}\text { Fault-free } \\
t \in[0 \mathrm{~s}, 7 \mathrm{~s})\end{array}$} & \multicolumn{2}{|c|}{ S1 } & \multicolumn{2}{|c|}{ S2 } \\
\hline & & $\begin{array}{c}\text { Fault transient } \\
\quad t \in[7 \mathrm{~s}, 8 \mathrm{~s}]\end{array}$ & $\begin{array}{l}\text { Steady state } \\
t \in[15 \mathrm{~s}, 20 \mathrm{~s}]\end{array}$ & $\begin{array}{l}\text { Fault transient } \\
\qquad t \in[7 \mathrm{~s}, 8 \mathrm{~s}]\end{array}$ & $\begin{array}{l}\text { Steady state } \\
t \in[15 \mathrm{~s}, 20 \mathrm{~s}]\end{array}$ \\
\hline PID & 0.0250 & 0.0343 & 0.0555 & 0.0250 & 0.0251 \\
\hline NRSC & $2.4546 \mathrm{e}-004$ & 0.0014 & 0.0018 & $2.4585 \mathrm{e}-004$ & $2.4687 \mathrm{e}-004$ \\
\hline FTSC & $2.4546 \mathrm{e}-004$ & $7.8270 \mathrm{e}-004$ & $2.4635 \mathrm{e}-004$ & $2.4585 \mathrm{e}-004$ & $2.4687 \mathrm{e}-004$ \\
\hline
\end{tabular}

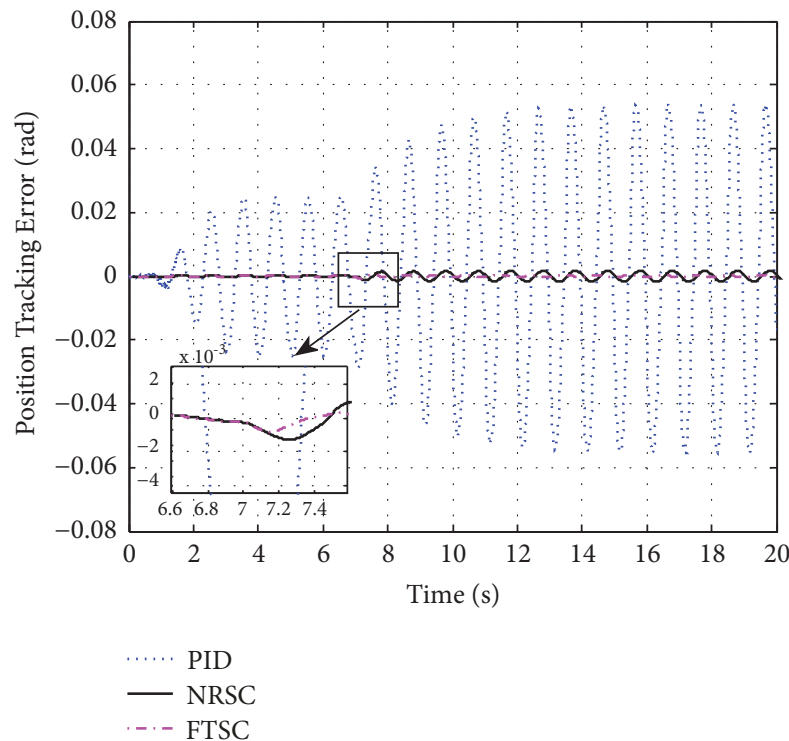

FIGURE 3: Position tracking error under scenario S1.

$$
d_{1}= \begin{cases}100 N & t<2 s \\ {[100+400 \sin (2 \pi t)] N} & t \geq 2 \mathrm{~s}\end{cases}
$$

and $d_{2}=400 \mathrm{~N}$.

For scenario S1, Figure 3 shows the position tracking error for three control schemes, and Table 3 summarizes the results of the maximum position tracking error for each scheme under different conditions. It is evident that the proposed FTSC scheme has the best position tracking performance among the three schemes.

In normal condition, the FTSC and NRSC are the same. As listed in Table 3, the maximum position tracking error for FTSC/NRSC is only $2.4546 \mathrm{e}-004 \mathrm{rad}$, much less than that for PID. This can be attributed to the robust control design in the FTSC/NRSC which dominates the model uncertainties better than PID.

When the severe internal leakage CMF occurs at $t_{\mathrm{f}}=7 \mathrm{~s}$, the dynamic performance of the closed-loop system begins to deteriorate rapidly, and this can be reflected from the variation of the performance indicator $V_{3}$ (see Figure 4). It is observed that the function value of $V_{3}$ experiences an abrupt variation at $t_{\mathrm{f}}=7 \mathrm{~s}$ and exceeds its upper bound $V_{\mathrm{r}}$ immediately, due to the occurrence of the CMF. Then, according to (67), the fault parameter vector and also the control parameter vector $\widehat{\boldsymbol{\theta}}$ for FTSC begin to be updated

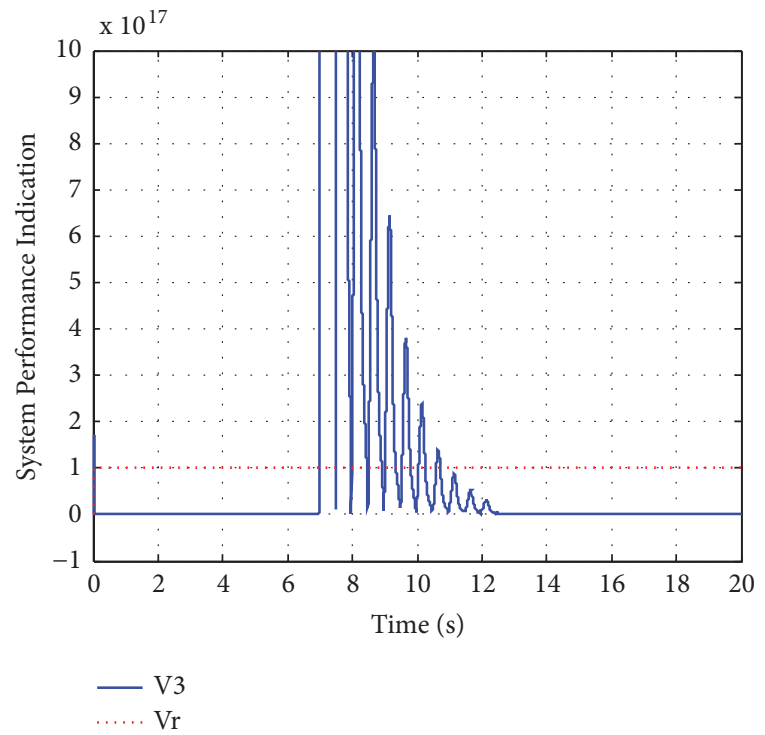

FIGURE 4: Indication of performance degradation under scenario S1.

online, and more control input is generated to compensate for the CMF effects. Therefore, the dynamic performance of the system under the control of the FTSC is gradually restored. As summarized in Table 3, after experiencing a small jump about 7.8270e-004 rad, the position tracking error for the FTSC finally converges to $2.4635 \mathrm{e}-004 \mathrm{rad}$ in steady state, much less than that for PID and for NRSC.

Figure 5 compares the output fighting forces for three control schemes. Table 4 summarizes the results of the maximum fighting force for each scheme under different conditions. Results indicate that the proposed FTSC scheme has the smallest fighting force among all the schemes no matter during fault-free or faulty time.

In normal condition, due to the introduction of the force synchronization strategy, the NRSC and FTSC can reduce the fighting force more effectively than PID. As shown in the second column of Table 4, the maximum fighting force is about $133 \mathrm{~N}$ for FTSC, smaller than that for PID.

Under fault condition, note that the CMF which has different effects on HAs may lead to response difference between two HAs and further enlarges the fighting force. Therefore, since the proposed FTSC scheme can accommodate the CMF better than the other two schemes, a more significant elimination of the fighting force between two HAs can be achieved naturally. As shown in Figure 5 and Table 4, the fighting force of the FTSC reaches its maximum 
TABLE 4: Maximum fighting force for three control schemes under different scenarios.

\begin{tabular}{|c|c|c|c|c|c|}
\hline \multirow{2}{*}{$\begin{array}{l}\text { Maximum } \\
\text { fighting force } \\
\text { (N) }\end{array}$} & \multirow[b]{2}{*}{$\begin{array}{l}\text { Fault-free } \\
t \in[0 \mathrm{~s}, 7 \mathrm{~s})\end{array}$} & \multicolumn{2}{|c|}{ S1 } & \multicolumn{2}{|c|}{ S2 } \\
\hline & & $\begin{array}{l}\text { Fault transient } \\
\qquad t \in[7 \mathrm{~s}, 8 \mathrm{~s}]\end{array}$ & $\begin{array}{l}\text { Steady state } \\
t \in[15 \mathrm{~s}, 20 \mathrm{~s}]\end{array}$ & $\begin{array}{c}\text { Fault transient } \\
\quad t \in[7 \mathrm{~s}, 8 \mathrm{~s}]\end{array}$ & $\begin{array}{l}\text { Steady state } \\
t \in[15 \mathrm{~s}, 20 \mathrm{~s}]\end{array}$ \\
\hline PID & 560.7653 & $2.5401 \mathrm{e}+004$ & $1.7943 e+004$ & $1.2109 \mathrm{e}+003$ & $1.2450 \mathrm{e}+003$ \\
\hline NRSC & 133.9697 & $9.7126 e+003$ & $8.1759 e+003$ & 146.9094 & 147.5323 \\
\hline FTSC & 133.9697 & $4.9884 \mathrm{e}+003$ & 133.0907 & 146.9094 & 147.5323 \\
\hline
\end{tabular}

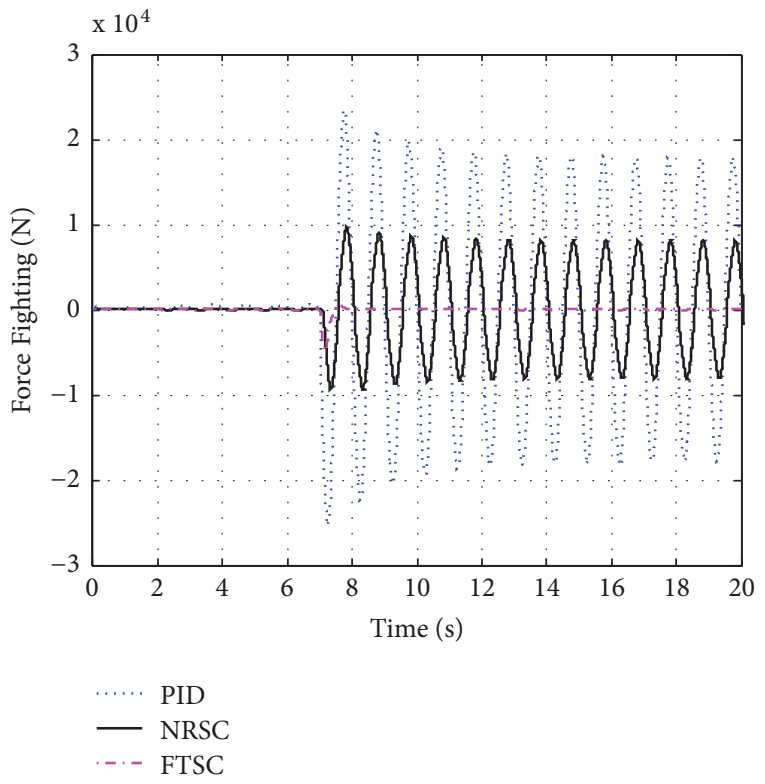

FIGURE 5: Force fighting between two HA channels under scenario S1.

value $4.9884 \mathrm{e}+003 \mathrm{~N}$, along with the occurrence of the severe internal leakage CMF, and gradually reduces to $133 \mathrm{~N}$ after entering steady state, far less than that of PID and NRSC.

Figure 6 shows the control inputs of the DRHAS for three schemes. Note that the fault effect in $\mathrm{HA}_{1}$ is more serious than that in $\mathrm{HA}_{2}$. Therefore, more control input is allocated to $\mathrm{HA}_{1}$ to compensate for the fault effect. As depicted in the upper plot of Figure 6, the control input ul for the proposed scheme is slightly larger than that for PID and for NRSC, but still maintains a relatively small value. Figure 7 presents the estimation result of the CMF and its real value. It can be found that the fault effect for each channel can be estimated correctly.

Under scenario S2, the DRHAS suffers from a slight internal leakage CMF. As illustrated in Figure 8, neither the maximum fault effect in $\mathrm{HA}_{1}$ nor that in $\mathrm{HA}_{2}$ exceeds the threshold. In this situation, according to inequalities (53) and (54), the leakage effects can be compensated by the robust control law (52). In Figure 9, the variation curve of the performance indicator $V_{3}$ further confirms that the system performance is still acceptable as the maximum value of $V_{3}$ does not exceed its upper bound. Therefore, based on (67), the parameters online adaptation in (52) will not be activated and the schemes FTSC and NRSC are the same.
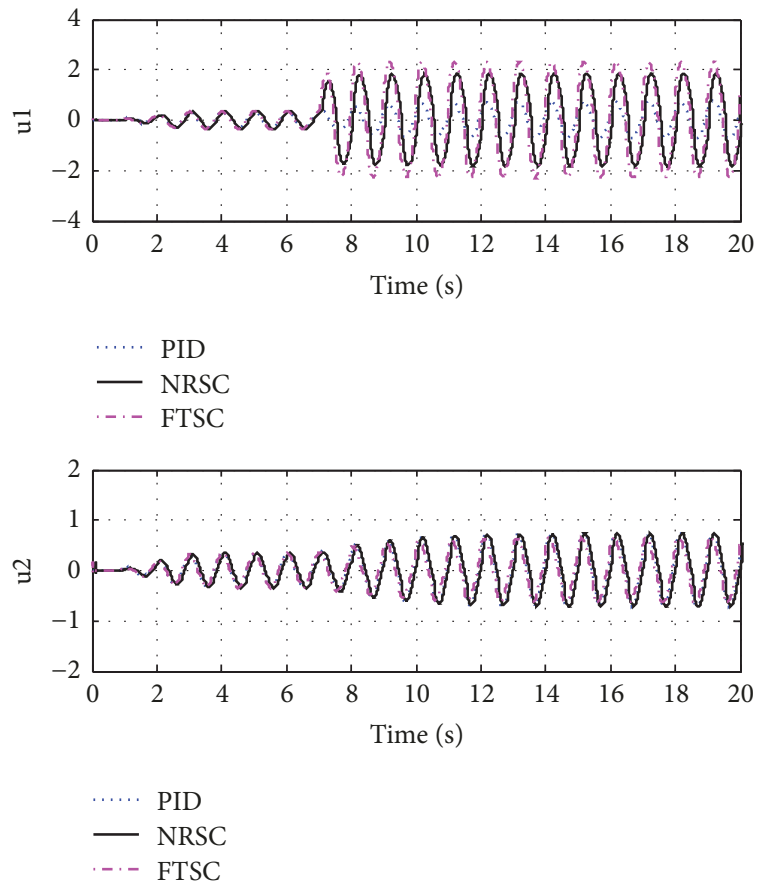

FIGURE 6: Control inputs of the DRHAS under scenario S1.

Figure 10 compares the position tracking error for three schemes. It is easy to see that the FTSC/NRSC has a much higher tracking accuracy than PID. As summarized in Table 3, by comparing the maximum tracking errors before and after the fault occurrence for each scheme, it seems that the slight internal leakage CMF has little effect on the position tracking accuracy of the system. Figure 11 shows the output fighting forces for three control schemes. Obviously, the FTSC/NRSC can reduce the fighting force more effectively in comparison with the PID, especially after the fault occurrence. As listed in Table 4, the maximum fighting force for PID during fault transient time is about $1.2109 \mathrm{e}+003 \mathrm{~N}$, almost ten times larger than that for FTSC/NRSC. This can be attributed to the robust control design as well as the force synchronization design for the FTSC/NRSC controller.

In conclusion, based on the simulation results, the proposed FTSC scheme can ensure the following:

(a) The closed-loop control system is robust to model uncertainties and slight internal leakage CMF.

(b) Fast and correct CMF estimation can be obtained when the performance degradation exceeds the predesigned tolerable level. 

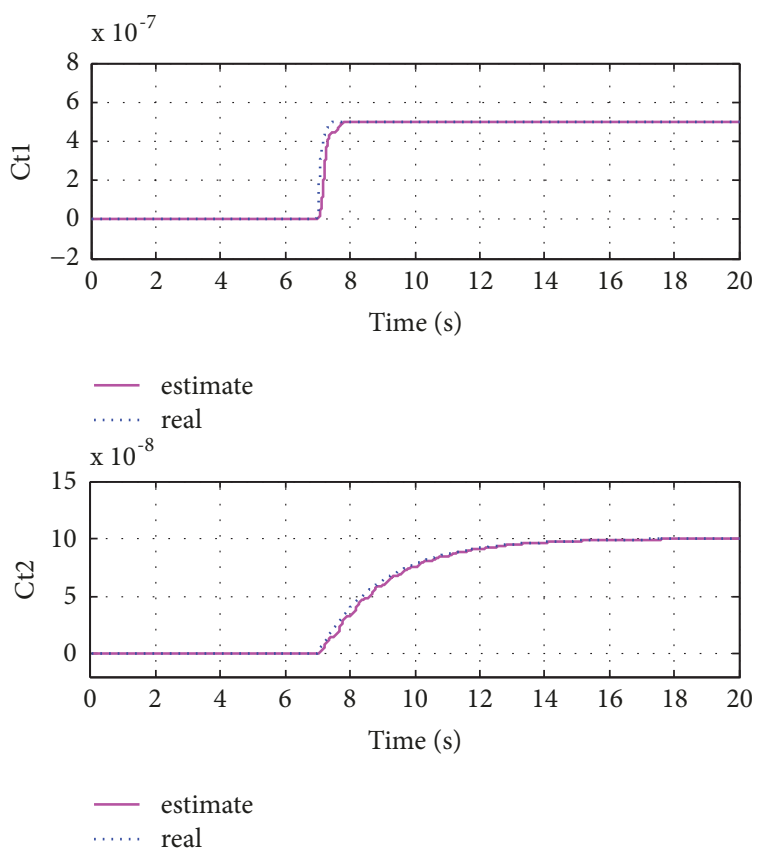

FIGURE 7: Estimate for severe internal leakage CMF under scenario S1.
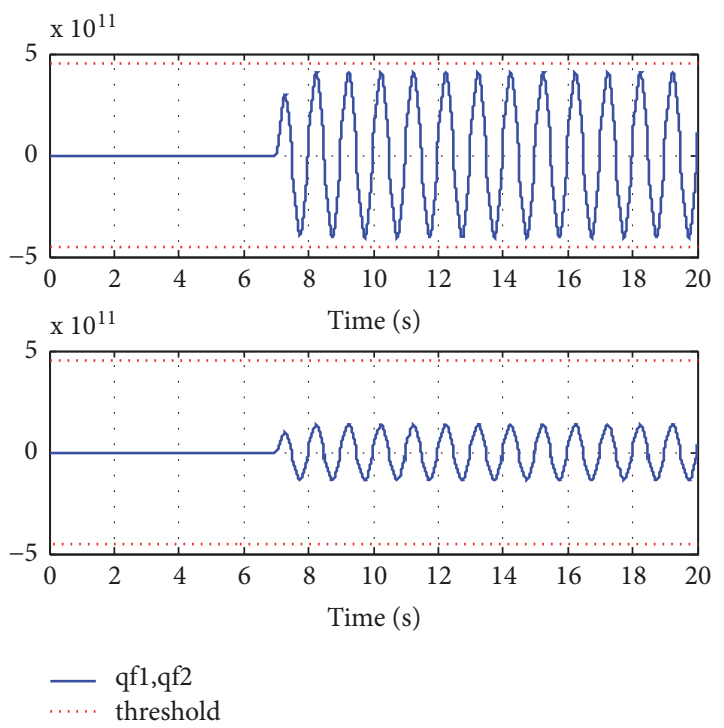

FIGURE 8: The internal leakage effects for two HA channels under scenario S2.

(c) A high position tracking accuracy and an effective reduction of fighting force between channels can be achieved no matter during fault-free or faulty time.

\section{Conclusions}

This paper proposes a fault-tolerant synchronization control scheme for a DRHAS, which operates on A/A mode and suffers from an internal leakage CMF, i.e., internal leakage faults occurring in both HAs simultaneously due to a common cause. Firstly, a desired trajectory generator is

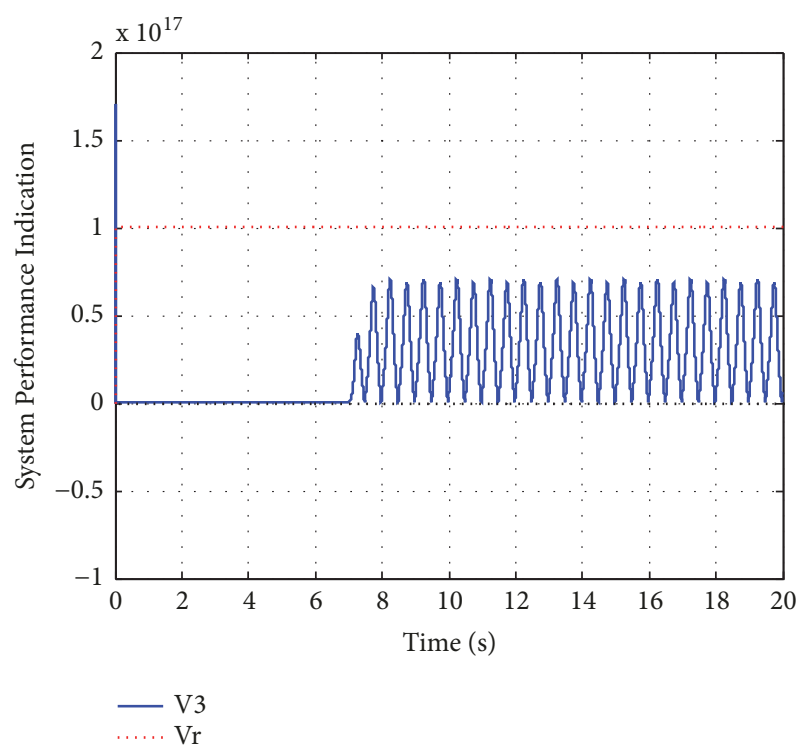

FIGURE 9: Indication of performance degradation under scenario S2.

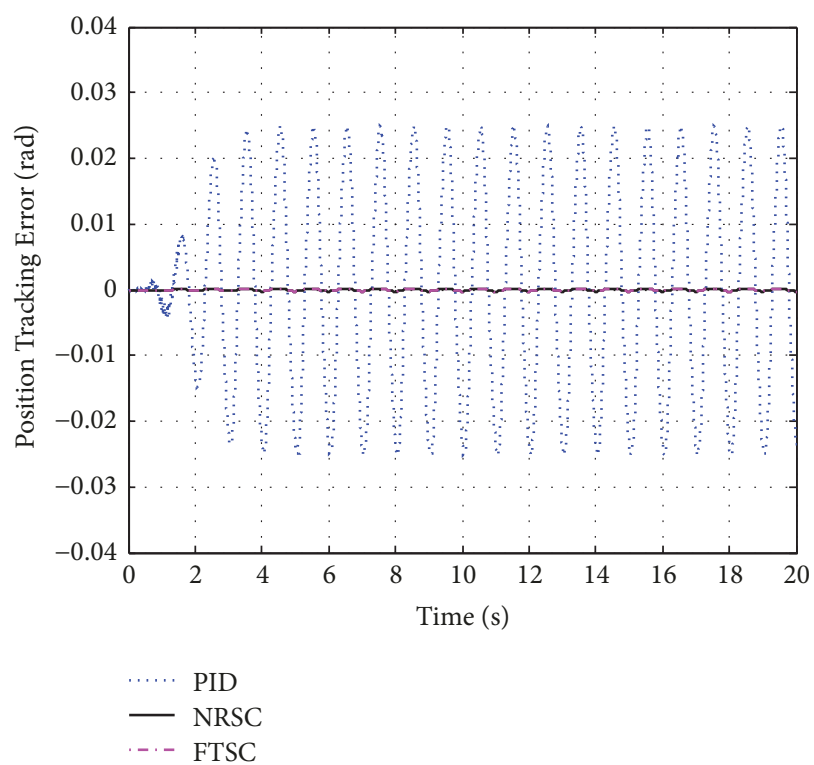

Figure 10: Position tracking error under scenario S2.

employed and two reference trajectories are generated for position tracking and for force outputs synchronization of HA channels, respectively. Secondly, a nonlinear adaptive robust FTSC controller is designed by employing backstepping method. A Lyapunov function based method is used to evaluate the control performance of the closed-loop system. As the degraded control performance induced by the CMF exceeds a tolerable level, the FTSC controller reconfigures its control action through parameters adaptation online to accommodate the fault. It has been verified that the proposed FTSC scheme can guarantee the bounded stability of output tracking error system under CMF. Finally, simulation results under two scenarios demonstrate the effectiveness of the proposed FTSC scheme. 


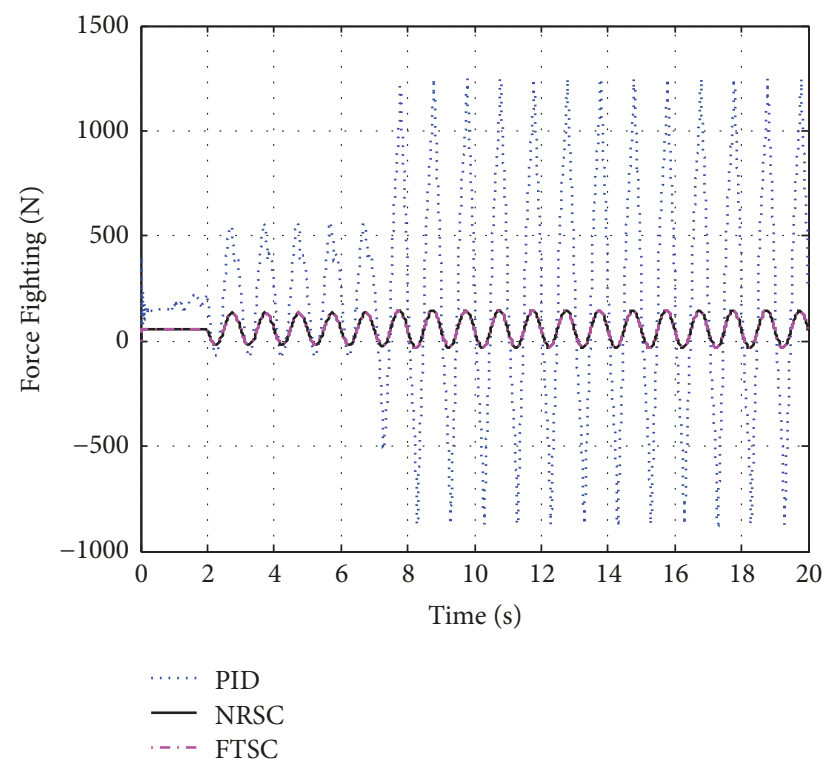

FIGURE 11: Force fighting between two HA channels under scenario S2.

\section{Data Availability}

The .jpg (the date type of the figures in the manuscript) data used to support the findings of this study are available from the corresponding author upon request.

\section{Conflicts of Interest}

The authors declare that there are no conflicts of interest regarding the publication of this paper.

\section{Acknowledgments}

This work was supported in part by the National Natural Science Foundation of China (Grant no. 61703341), China Postdoctoral Science Foundation (Grant no. 2018M633576), Natural Science Basic Research Plan in Shaanxi Province of China (Grant no. 2018JQ6008), and the Fundamental Research Funds for the Central Universities (Grant no. 3102017OQD025).

\section{References}

[1] H. Qi, Y. Fu, X. Qi, and Y. Lang, "Architecture optimization of more electric aircraft actuation system," Chinese Journal of Aeronautics, vol. 24, no. 4, pp. 506-513, 2011.

[2] D. R. Ryder, "Redundancy actuator development study," Tech. Rep., Boeing Commercial Airplane Corp, Seattle, WA, NASA, 1973.

[3] S. Mitra, N. R. Saxena, and E. J. McCluskey, "Commonmode failures in redundant VLSI systems: A survey," IEEE Transactions on Reliability, vol. 49, no. 3, pp. 285-295, 2000.

[4] C. Feldstein and J. Muzio, "Development of a fault tolerant flight control system," in Proceedings of the 23rd IEEE/AIAA Digital Avionics Systems Conference, pp. 25-40, Salt Lake City, UT, USA, Oct 2004.
[5] J. H. Lala and R. E. Harper, "Architectural Principles for SafetyCritical Real-Time Applications," Proceedings of the IEEE, vol. 82, no. 1, pp. 25-40, 1994.

[6] M. Karpenko and N. Sepehri, "Quantitative fault tolerant control design for a leaking hydraulic actuator," Journal of Dynamic Systems, Measurement, and Control, vol. 132, no. 5, pp. 626-634, 2010.

[7] M. Karpenko and N. Sepehri, "Robust position control of an electrohydraulic actuator with a faulty actuator piston seal," Journal of Dynamic Systems, Measurement, and Control, vol. 125, no. 3, pp. 413-423, 2003.

[8] S. Gayaka and B. Yao, "Fault detection, identification and accommodation for an electro-hydraulic system: an adaptive robust approach," in Proceedings of the 17th World Congress, International Federation of Automatic Control (IFAC'08), vol. 41, pp. 13815-13820, Seoul, Korea, 2008.

[9] J. Yao, G. Yang, and D. Ma, "Internal leakage fault detection and tolerant control of single-rod hydraulic actuators," Mathematical Problems in Engineering, vol. 2014, Article ID 345345, 14 pages, 2014.

[10] V. Mahulkar, D. E. Adams, and M. Derriso, "Adaptive fault tolerant control for hydraulic actuators," in Proceedings of the 2015 American Control Conference, ACC 2015, pp. 2242-2247, Chicago, IL, USA, July 2015.

[11] S. A. Nahian, D. Q. Truong, P. Chowdhury, D. Das, and K. K. Ahn, "Modeling and fault tolerant control of an electrohydraulic actuator," International Journal of Precision Engineering and Manufacturing, vol. 17, no. 10, pp. 1285-1297, 2016.

[12] Y. Zhang and J. Jiang, "Bibliographical review on reconfigurable fault-tolerant control systems," Annual Reviews in Control, vol. 32 , no. 2, pp. 229-252, 2008.

[13] Z. Zhao, Active Fault Tolerant Control of an Electro-Hydraulic Driven Elevator Based on Robust Adaptive Observers, Concordia University, Montreal, Quebec, Canada, 2010, Ph.D. dissertation.

[14] Z. Zhao, W.-F. Xie, H. Hong, and Y. Zhang, "A disturbancedecoupled adaptive observer and its application to faulty parameters estimation of a hydraulically driven elevator," International Journal of Adaptive Control and Signal Processing, vol. 25, no. 6, pp. 519-534, 2011.

[15] H. Wang, H. R. Karimi, P. X. Liu, and H. Yang, "Adaptive neural control of nonlinear systems with unknown control directions and input dead-zone," IEEE Transactions on Systems, Man, and Cybernetics: Systems, pp. 1-11, 2017.

[16] H. Wang, P. X. Liu, and S. Li, "Adaptive neural output-feedback control for a class of nonlower triangular nonlinear systems with unmodeled dynamics," IEEE Transactions on Neural Networks and Learning Systems, vol. 29, no. 8, pp. 3658-3668, 2018.

[17] X. Zhao, P. Shi, and X. Zheng, "Fuzzy Adaptive Control Design and Discretization for a Class of Nonlinear Uncertain Systems," IEEE Transactions on Cybernetics, vol. 46, no. 6, pp. 1476-1483, 2016.

[18] X. Zhao, X. Wang, G. Zong, and H. Li, "Fuzzy-approximationbased adaptive output-feedback control for uncertain nonsmooth nonlinear systems," IEEE Transactions on Fuzzy Systems, pp. 1-12, 2018.

[19] J. Zhao, B. Jiang, and F. Xie, "Adaptive sliding mode backstepping control for near space vehicles considering engine faults," Journal of Systems Engineering and Electronics, vol. 29, no. 2, pp. 343-351, 2018. 
[20] X. Li, J. Yao, and C. Zhou, "Output feedback adaptive robust control of hydraulic actuator with friction and model uncertainty compensation," Journal of The Franklin Institute, vol. 354, no. 13, pp. 5328-5349, 2017.

[21] J. Yao, Z. Jiao, and B. Yao, "Nonlinear adaptive robust backstepping force control of hydraulic load simulator: Theory and experiments," Journal of Mechanical Science and Technology, vol. 28, no. 4, pp. 1499-1507, 2014.

[22] Y. Fu, Y. Pang, H. Liu, and Y. Zhang, "Force fighting research of dual redundant hydraulic actuation system," in Proceedings of the 2010 International Conference on Intelligent System Design and Engineering Application (ISDEA), pp. 762-766, Changsha, Hunan, China, October 2010.

[23] G. Jacazio and L. Gastaldi, "Equalization techniques for dual redundant electrohydraulic servo actuator for flight control systems," in Proceedings of the BATH/AMSE 2008 Symposium On Fluid Power and Motion Control, pp. 543-557, Bath, UK, 2008.

[24] C. Shi, X. Wang, S. Wang, J. Wang, and M. M. Tomovic, "Adaptive decoupling synchronous control of dissimilar redundant actuation system for large civil aircraft," Aerospace Science and Technology, vol. 47, pp. 114-124, 2015.

[25] O. Cochoy, S. Hanke, and U. B. Carl, "Concepts for position and load control for hybrid actuation in primary flight controls," Aerospace Science and Technology, vol. 11, no. 2, pp. 194-201, 2007.

[26] X. Wang, R. Liao, C. Shi, and S. Wang, "Linear extended state observer-based motion synchronization control for hybrid actuation system of more electric aircraft," Sensors, vol. 17, no. 11, pp. 2444-2459, 2017.

[27] K. Guo, J. Wei, J. Fang, R. Feng, and X. Wang, "Position tracking control of electro-hydraulic single-rod actuator based on an extended disturbance observer," Mechatronics, vol. 27, pp. 4756, 2015.

[28] W. Kim, D. Shin, D. Won, and C. C. Chung, "Disturbanceobserver-based position tracking controller in the presence of biased sinusoidal disturbance for electrohydraulic actuators," IEEE Transactions on Control Systems Technology, vol. 21, no. 6, pp. 2290-2298, 2013.

[29] M. Krstic, I. Kanellakopoulos, and P. V. Kokotovic, Nonlinear and Adaptive Control, Wiley, New York, NY, USA, 1995.

[30] B. Yao and M. Tomizuka, "Adaptive robust control of SISO nonlinear systems in a semi-strict feedback form," Automatica, vol. 33, no. 5, pp. 893-900, 1997. 


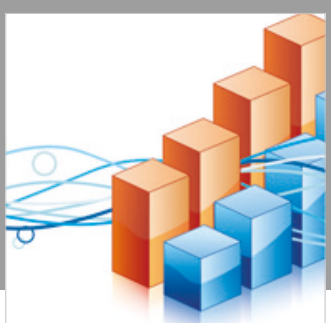

Advances in

Operations Research

\section{-n-m}
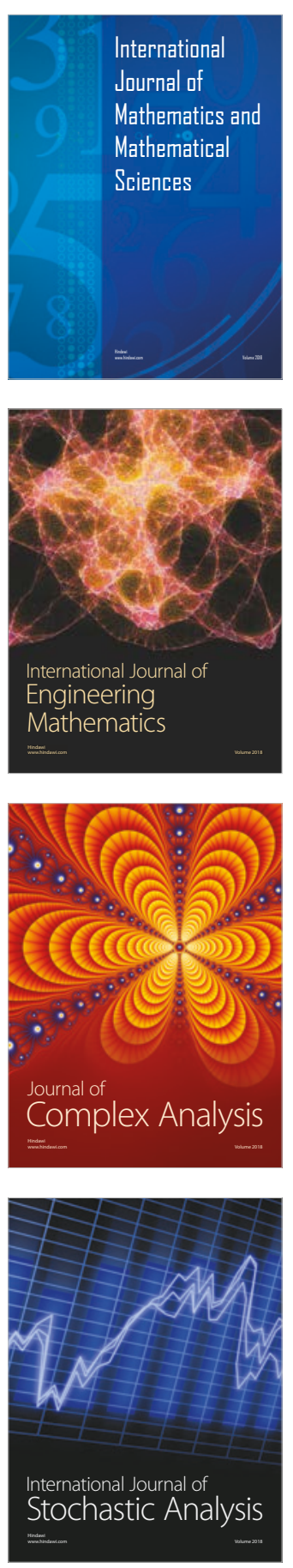
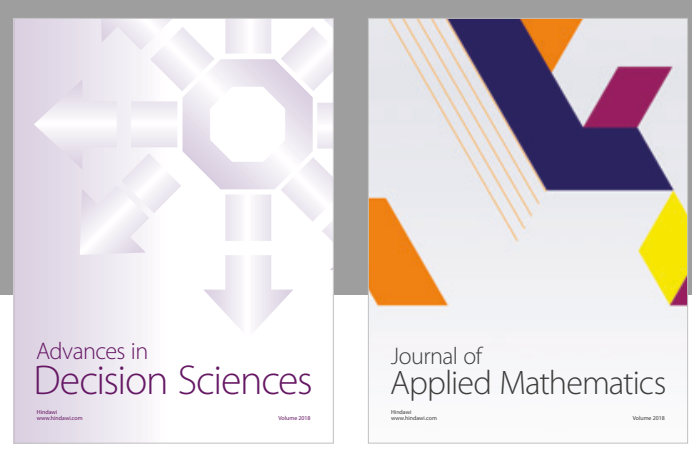

Journal of

Applied Mathematics
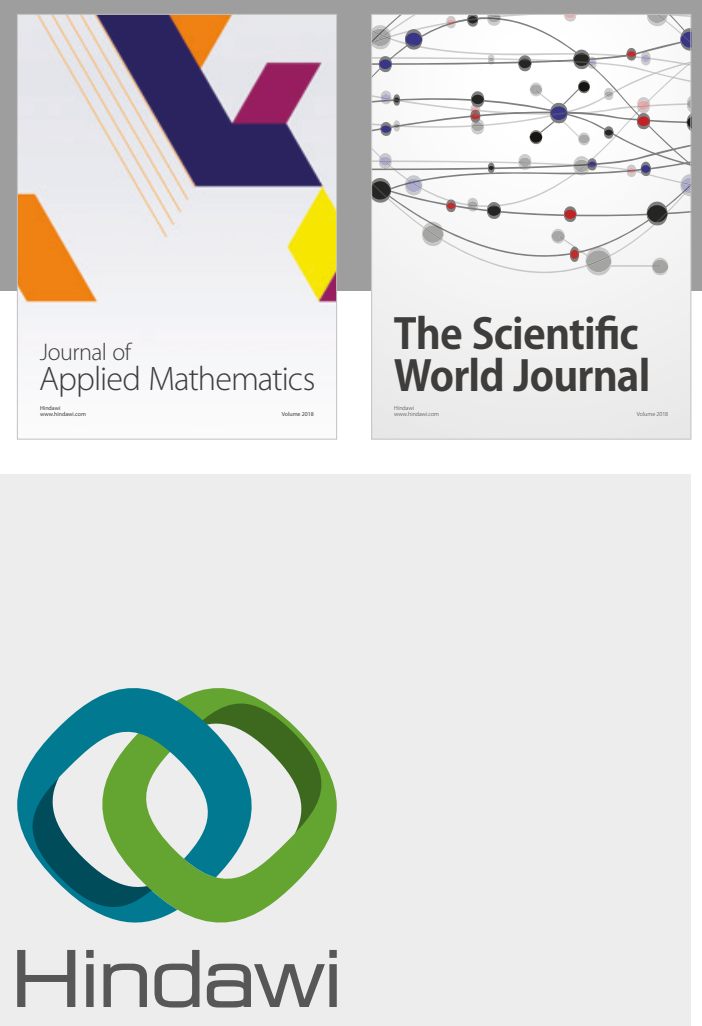

Submit your manuscripts at

www.hindawi.com

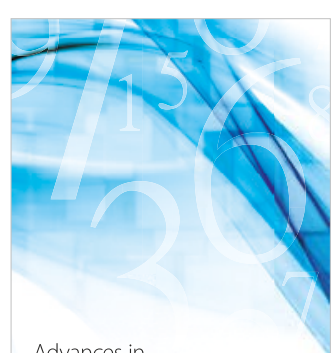

Advances in
Numerical Analysis
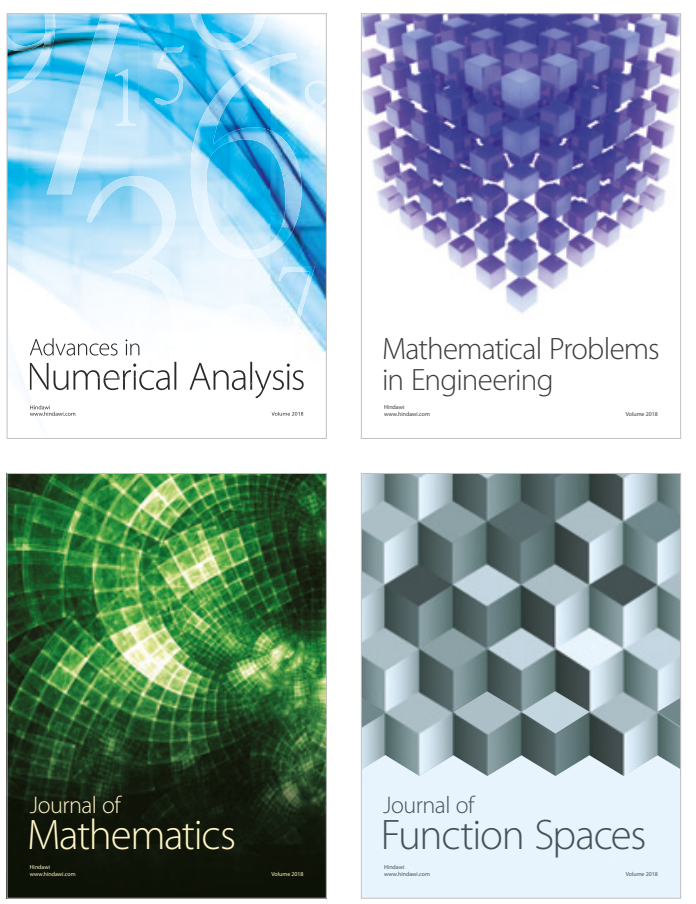

Mathematical Problems in Engineering

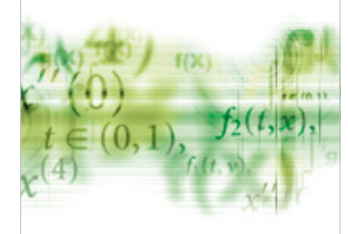

International Journal of

Differential Equations

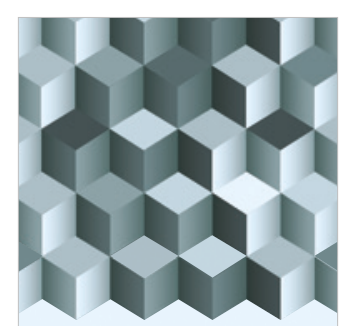

Journal of

Function Spaces

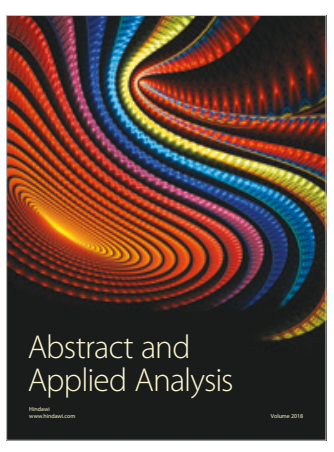

The Scientific

World Journal

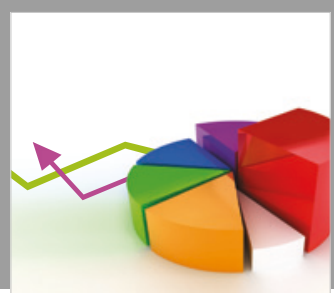

Journal of

Probability and Statistics
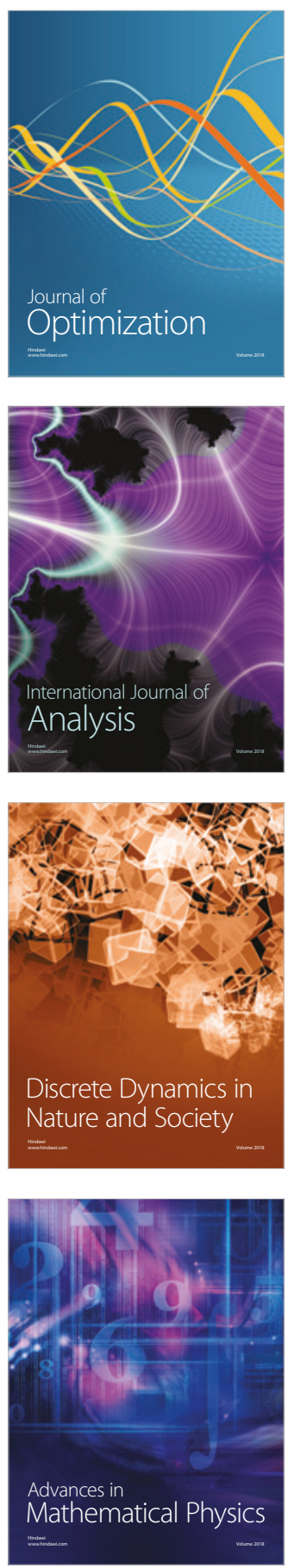